\title{
Wer hat den Dyotheletismus erfunden?
}

\section{Zur Frage der Authentizität der Apologia Honorii Papst Iohannes' IV. (640-642)}

Abstract: This article examins the hypothesis published in 2013 by Marek Jankowiak, according to which Pope John IV in his so-called Apologia Honorii (CPL 1729) and Maximos Homologetes independently "invented" a dyotheletic Christology for the first time. For that purpose, this letter by John IV is analysed with regard to its sources, its text and the context of its composition. It is shown that the letter, which is preserved only in a Latin retranslation from Greek by Anastasius Bibliothecarius made in $874 / 75$, originally referred only the monothelistic statement of Pope Honorius to the human nature of Christ. The dyotheletic statements, which can also be found in the text, are the result of later updating. This updating begins already in the 7th century in the circle of Maximos' followers. Here, as well as in the context of the oldest tradition at Anastasius Biliothecarius in the so-called Photian Schism, the conflict-oriented interest in an unlimited authority of the papacy stands in the background. The "invention" of the theologoumenon of a double will in Christ should be assigned exclusively to Maximos Homologetes.

Adresse: Prof. Dr. Heinz Ohme, Humboldt-Universität zu Berlin, Theologische Fakultät, Burgstr. 26, 10178 Berlin, Deutschland; Heinz.Ohme@rz.hu-berlin.de

Als im Jahre 638 Patriarch Sergios von Konstantinopel (610-638), ${ }^{1}$ Papst Honorius I. (625-638) $)^{2}$ und Patriarch Sophronios von Jerusalem $(633-638)^{3}$ gestorben waren,

1 J.L. van Dieten, Geschichte der Patriarchen von Sergios I. bis Johannes VI. (610-715). Amsterdam 1972, 1-56; F. Winkelmann, Der monenergetisch-monotheletische Streit. Berliner Byzantinistische Studien, 6. Frankfurt/M. 2001, 258-260.

2 G. KREUZER, Die Honoriusfrage im Mittelalter und in der Neuzeit. Stuttgart 1975.

3 CH. v. Schönborn, Sophrone de Jérusalem. Vie monastique et confession dogmatique. Théologie historique, 20. Paris1972; P. Allen, Sophronius of Jerusalem and seventh-century heresy. 
erfolgte ein dramatischer Wechsel von den bisherigen Hauptakteuren des sog. monenergetisch-monotheletischen Streites $^{4} \mathrm{zu}$ einer neuen Generation von Theologen und Kirchenpolitikern mit wesentlich größerer Konfliktbereitschaft. Zu diesen gehörte der neugewählte Konstantinopler Patriarch Pyrrhos (638641.654). ${ }^{5}$ Dieser versuchte umgehend, die von seinem Vorgänger Sergios verfasste und von Kaiser Herakleios (610-641) ${ }^{6}$ als Gesetz publizierte dogmatische Darlegung des Glaubens, die sog. Ekthesis ${ }^{7}$ von 638 (636?), gesamtkirchlich durchzusetzen. Dazu berief er Anfang 639 eine Synode nach Konstantinopel ein, die die Lehre der Ekthesis bestätigte. Abwesenden Bischöfen im Osten wie im Westen wurden die Akten dieser Synode „zusammen mit unserem Rundschreiben“ zur Unterschrift zugesandt. ${ }^{8}$ Papst Iohannes IV. (24.12.640-12.10.642) ${ }^{9}$ nahm dies zum Anlass eines Protestbriefes ${ }^{10}$ an die Kaiser Konstantin III. und Herakleios (Heraklonas) (Jan./Febr. 641-Juni 641), in dem er beklagte, dass der gesamte Westen in heller Aufregung sei und daran Anstoß nehme, dass ,unser Bruder, der Patriarch Pyrrhos, in seinem überallhin verschickten Schreiben gewisse neue Dinge verkündet, die gegen die regula fidei sind. “Vor allen Dingen aber empörte sich der Papst darüber, dass Pyrrhos „unseren Vorgänger heiligen Angedenkens, Papst

The Synodical Letter and other documents. Oxford 2009; P. Воотн, Crisis of empire: doctrine and dissent at the end of Late Antiquity. Berkeley u.a. 2013; SснӧNBORN ebd. 97 Anm. 136 plädiert für 639 als Todesjahr des Sophronios.

4 Winkelmann, Streit (wie oben Fußnote 1); Ch. Lange, Mia Energeia. Untersuchungen zur Einigungspolitik des Kaisers Heraclius und des Patriarchen Sergius von Constantinopel. Studien und Texte zu Antike und Christentum, 66. Tübingen 2012; M. JANKowIAK, Essai d'histoire politique du monothélisme. Diss. Paris/Warschau 2009 [ungedruckt].

5 Prosopographie der mittelbyzantinischen Zeit. Erste Abteilung 641-867. Nach Vorarbeiten F. Winkelmanns erstellt von R.-J. LiLIE, C. LudWig, TH. PRATSCH, I. Rochow, Bd. 1-6. Berlin 19992002, Nr. 6386 (im Weiteren: PmbZ); van Dieten, Geschichte (wie oben Fußnote 1), 57-75. 6 W.E. KaEgI, Heraclius. Emperor of Byzantium. Cambridge 2003.

7 F. DöLGER/ A. E. MÜLLER, Regesten der Kaiserurkunden des oströmischen Reiches. I, 1 Regesten 565-867. 2. Aufl. besorgt u. Mitarbeit v. J. Preiser-Kapeller u. A. Riehle v. A.E. Müller. München 2009, Reg. 211. Dieses Gesetz verbot jeden Streit über das Energienproblem sowie eine numerische Verwendung des Energiebegriffes für das göttliche und menschliche Wirken Jesu Christi und suchte den Konsens in der vermeintlich unstrittigen Überzeugung von dem einen einheitlichen Willen und Wollen Jesu. Zur Ekthesis vgl. Winkelmann, Streit (wie oben Fußnote 1) Nr. 50; LANGE, Mia Energeia (wie oben Fußnote 4), 606-614. Воотн, Crisis (wie oben Fußnote 3) 239-241, hat unter Berufung auf JANKowiaK, Essai d'histoire (wie oben Fußnote 4) 146-149, die Ekthesis jetzt auf 636 datiert.

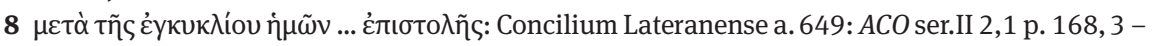
170, 7. 168,29; Winkelmann, Streit (wie oben Fußnote 1) Nr. 56.

9 PmbZ Nr. 2689.

10 Iohannes IV., ep. Constantino Imp.: PL 129, 561-566 (CPL 1729; CPG 9383); WinkeLMANN, Streit (wie oben Fußnote 1) Nr. 69. 
Honorius, für seine eigene Auffassung heranzieht, was doch der Gesinnung des katholischen Vaters völlig fremd war. "11 Pyrrhos hatte demnach zur Unterstützung seines Monotheletismus auf den 1. Brief ${ }^{12}$ des Honorius an Patriarch Sergios verwiesen, in dem der Papst zu dem Schluss gekommen war: „Deshalb bekennen wir auch einen Willen des Herrn Jesus Christus“. ${ }^{13}$ Dies aufnehmend, hatte Sergios den Text der Ekthesis formuliert.

Die frühesten Zeugnisse des Widerspruchs gegen die Theologie des einen Willens Jesu Christi datieren aus den Jahren 640/41 und finden sich in einigen Schriften des Maximos Homologetes (ca. 579-662) ${ }^{14}$ und bei Papst Iohannes IV. Maximos Homologetes hat in seinen in diesen Jahren entstandenen sog. Opuscula theologica et polemica $6,{ }^{15} 7^{16}$ und $20^{17}$ im Widerspruch zur Ekthesis und in

11 Iohannes IV., ep. Constantino Imp.: omnes occidentales partes scandalizate turbantur, fratre nostro Pyrrho patriarcha, per litteras suas huc atque illuc transmissas, nova quaedam et praeter regulam fidei praedicante, et proprium sensum quasi sanctae memoriae Honorium papam decessorem nostrum attrahere festinante, quod a mente catholici Patris erat penitus alienum (PL 129, 561 C13-D5).

12 Honorius I., ep. Sergio Patr.: ACO ser. II 2,2 p. 548, 1 - 558, 3 (Riedinger); WinkelmanN, Streit (wie oben Fußnote 1) Nr. 44; deutsche Übersetzung: KreUzER, Honoriusfrage (wie oben Fußnote 2), 32-47.

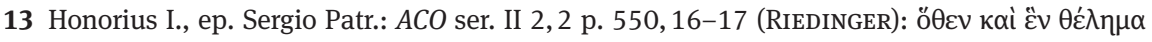
ó Schreiben von Ende 633/Anfang 634 (ACO ser. II 2, 2 p. 534, 1 - 546, 25) den seit der Union des alexandrinischen Patriarchen Kyros (631-642; PmbZ Nr. 4213) mit den ägyptischen Severianern (Theodosianern) vom 3.6.633 ausgebrochenen Streit über die dort beschlossene Formel der

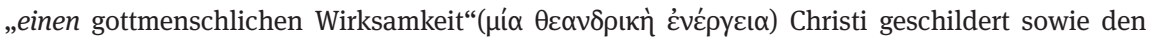
inzwischen im Osten erreichten Konsens, in Zukunft keine numerischen Aussagen mehr über die Anzahl von Energien in Christus zu machen und stattdessen nur noch von dem „einen, das

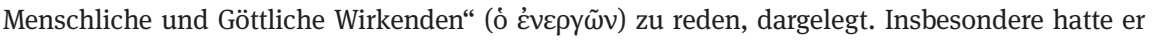

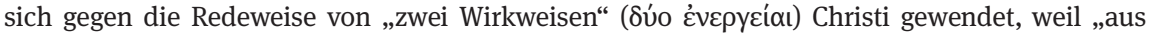
diesem Ausdruck folgt, ebenfalls zwei Willen ( $\delta$ v́o $\theta \varepsilon \lambda \hat{\mu} \mu \alpha \tau \alpha)$ zu verkünden, die einander entgegengesetzt seien ... und damit zwei das Entgegengesetzte Wollende einzuführen, was gottlos ist“ (542,13-14.15-16). Honorius stimmte Sergios in allem zu und kam aus der Überzeugung, dass es „ein und derselbe ist, der in der göttlichen und menschlichen Natur wirkt“ (556,14-15), zu der o.g. Spitzenaussage.

14 PmbZ Nr. 4921; P. Allen / B. NeIL (Hrsg.), The Oxford Handbook of Maximus the Confessor. Oxford 2015.

15 Maximus Conf., Opusc. theol. et pol. 6: PG 91, 65-69.Vgl. dazu WinkeLmann, Streit (wie oben Fußnote 1) Nr. 66; M. Jankowiak/Рн. Воотн, A new date-list of the Works of Maximus the Confessor, in: AlLEN/Neil, Handbook (wie oben Fußnote 14) 19-83. Nr. 59.

16 Maximus Conf., Opusc. theol. et pol. 7 an den zyprischen Diakon Marinos: PG 91, 69B-89B. Vgl. dazu Winkelmann, Streit (wie oben Fußnote 1) Nr. 59; Jankowiak/Booth, A new date-list (wie oben Fußnote 15) Nr. 41. 
Opusculum 20 zur Verteidigung des Honorius aus der chalcedonensischen ZweiNaturen-Lehre und einem von seinen Merkmalen her definierten ontologischen Naturbegriff die theologische Notwendigkeit der Rede von einem „doppelten“

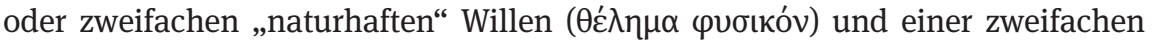

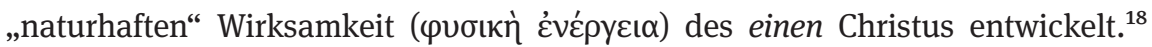
Papst Iohannes IV. hat i.J. 641 eine römische Synode einberufen, die nach dem Synodicon vetus „Sergios, Kyros und Pyrrhos anathematisierte und zwei Naturen und zwei Wirkweisen unseres Herrn und Gottes Jesus Christus verkündete. "19 In dem bereits genannten Brief ${ }^{20}$ an die Kaiser, der als Apologia Honorii in die Geschichte einging, hat der Papst weiterhin eine Interpretation des 1. Honoriusbriefes vorgenommen, die dessen Formulierung von dem einen Willen Christi ausschließlich auf dessen menschliche Natur bezog. Gleichzeitig aber bietet dieser Brief ein elaboriertes dyenergetisches und dyotheletisches Bekenntnis. Daraus hat in jüngster Zeit Marek Jankowiak die These entwickelt, ,that the first statements of the two wills of Christ date only from 641, when pope John IV. and Maximus the Confessor independently composed their apologies for pope Honorius“. ${ }^{21}$

Bereits seit langem ist allerdings auf Unstimmigkeiten und Widersprüche in den Quellen zu den Maßnahmen Iohannes' IV. hingewiesen worden. Schon Carl Joseph HEFELE hatte festgestellt, dass es auf der römischen Synode von 641 nicht zu den genannten namentlichen Anathematismen gekommen sein kann, weil der Papst in seinem Brief an die Kaiser den Konstantinopler Patriarchen als „unseren Bruder Pyrrhos“ und dessen Vorgänger als „Sergius reverendae memoriae patriarcha“ bezeichnet. ${ }^{22}$ Theologische Widersprüche in der Apologia Honorii hatte schon Erich Caspar thematisiert und dafür das „logische Unvermögen“ des

17 Maximus Conf., Opusc. theol. et pol. 20 an den zyprischen Presbyter Marinos: PG 91, 228B245D.Vgl. dazu Winkelmann, Streit (wie oben Fußnote 1) Nr. 60; Jankowiak/Booth, A new datelist (wie oben Fußnote 15) Nr. 42.

18 Die beiden Naturen Christi, ,aus denen und in denen und welche er ist“, seien stets zu unterscheiden, auch wenn diese durch wechselseitiges Zusammenwachsen und gegenseitige Durchdringung zu einem einheitlichen Wirken und Wollen vollständig vereint seien. Maximus Conf., Opusc. theol. et pol. 6: PG 91, 68 A; Opusc. theol. et pol. 7: PG 91, 76 A, 80C, 84B, 88 A; Opusc. theol. et pol. 20: $P G$ 91, 233AB; 237CD.

19 J. Duffy/J. PARKER (Hrsg.), The Synodicon vetus. CFHB XV. Washington 1979, Nr. 137 (s. dazu unten S.116-118); WinkelmanN, Streit (wie oben Fußnote 1) Nr. 67b.

20 S. oben Fußnote 10.

21 M. Jankowiak, The invention of Dyotheletism. Studia Patristica 63 (2013) 335-342, hier 335. Ähnlich bereits Ders., Essai (wie oben Fußnote 4) 183-190. Die Apologia Honorii sei ,le premier text romain qui parle avec tout de clarité de deux volontés du Christ (ebd., 189).

22 Iohannes IV., ep. Constantino Imp.: PL 129, 561D, 562C4. C. J. HEFELE / H. LECLERCQ, Histoire des Conciles III/1. Paris 1909, 393. 
Papstes verantwortlich gemacht, welches er auf das ,in Unbildung versunkene Rom des 7. Jh.s“ zurückführte. ${ }^{23}$ M. Jankowiak hat dieses Urteil nochmals zugespitzt. ${ }^{24}$ Es muss deshalb überraschen, dass bislang nicht die Frage nach der Authentizität des überlieferten Textes der Apologia Honorii aufgeworfen wurde, zumal der Liber Pontificalis von der Synode und dem Brief Iohannes' IV. nichts weiß. ${ }^{25}$ Im Folgenden soll deshalb der Text der Apologia Honorii auf seine Authentizität hin überprüft werden. Damit eng verknüpft ist die Frage nach der Herkunft des Textes und seinen Quellen, die in ihrem jeweiligen historischen Kontext zu betrachten sind. Deshalb werden zuerst die Quellen der Apologia Honorii Papst Iohannes' IV. gesichtet (1.) und dann ihr Textbestand einer kritischen Analyse unterzogen (2.). Die dabei gewonnen Einsichten werden (3.) für die Überprüfung der Quellen zur römischen Synode von 641 fruchtbar gemacht. Weil sich bei den Schritten 1-3 der sog. photianische Streit als Bezugspunkt herauskristallisiert, muss dieser hinsichtlich der Bedeutung der Orthodoxie des Honorius in dieser Kontroverse in den Blick genommen werden (4.). Von daher wird sich schließlich die Frage beantworten lassen (5.), wie der überlieferte Text der Apologia Honorii entstanden ist und ob tatsächlich die römische Kirche unter Iohannes IV. parallel und unabhängig von Maximos Homologetes den Dyotheletismus ,erfunden“ hat.

\section{Die Quellen der Apologia Honorii Papst Iohannes' IV.}

Der Brief Papst Iohannes' IV. an die Kaiser Konstantin III. und Herakleios (Heraklonas) ist literarisch erstmals belegt in den 874/75 entstandenen sog. Collectanea $^{26}$ des päpstlichen Kanzlers und Diplomaten Anastasius Bibliothecarius $(\dagger$

23 E. CASPAR, Die Lateransynode von 649. ZKG 51 (1932) 75-137: 107.112. Vgl. auch DERS., Geschichte des Papsttums II. Tübingen 1933, 541.

24 Jankowiak, Invention (wie oben Fußnote 21) 340: „The logic of John IV's letter is flawed, his definitions are vague, and the main issue of the will(s) of the two natures of Christ is eschewed." 25 Vgl. Liber Pontificalis 74 (Duchesne I 330). Bis in die neueste Literatur werden der Text der Apologia Honorii und die Angaben des Synodicon vetus unkritisch übernommen. Vgl. z. B. R. PRICE / PH. Воотн / C. Cubitt, The Acts of the Lateran Synod of 649, transl. by R. PRICE. Translated Text for Historians, 61. Liverpool 2014, Introduction, 12 mit Anm. 33 (Рн. Воотн); 50 mit Anm.144 (C. CuBITT).

26 Anastasius Bibl., Collectanea: PL 129, 557-690. 
ca. 879). ${ }^{27}$ Es handelt sich dabei um Übersetzungen griechischer Texte ins Lateinische, die Anastasius für den Hofhistoriographen Papst Iohannes VIII. (872-882), Iohannes Diaconus, angefertigt hatte. In einem Brief ${ }^{28}$ an diesen erklärt Anastasius, welche Texte er übersetzt hat und warum. ${ }^{29}$ Es handelt sich insgesamt um 15 Texte $^{30}$ unterschiedlicher Länge und Vollständigkeit, die allesamt den monenergetisch-monotheletischen Streit betreffen.

Neben dem (1) Brief Iohannes' IV. hat Anastasius Bibliothecarius folgende Texte übersetzt und in seine Sammlung aufgenommen: ${ }^{31}$

(2) Einen Auszug aus dem Tomus dogmaticus des Maximos Homologetes an den zyprischen Presbyter Marinos vom Jahre 641 (CPG 7697.20). ${ }^{32}$

(3) Einen Auszug aus einem Brief des Maximos Homologetes an Petros Illustrios von Jahre 645 (CPG 7697.12). ${ }^{33}$ Der Brief ist nur in dieser Gestalt in der Übersetzung des Anastasius erhalten.

(4) Einen Auszug aus einem Brief des Maximos Homologetes an den zyprischen Presbyter Marinos von ca. 643-646 (CPG 7697.10). ${ }^{34}$ Der Text existiert nur in dieser fragmentarischen Gestalt und lateinischen Übersetzung.

(5) Die Epistula synodica des Papstes Theodorus I. (642-649) an Patriarch Paulos II. von Konstantinopel (641-653) vom Jahre 643. ${ }^{35}$ Der Brief existiert nur in dieser Rückübersetzung.

27 Zu Anastasius Bibl. vgl. PmbZ Nr. 341. 20341; B. NeIL, Seventh-century popes and martyrs. The political hagiography of Anastasius Bibliothecarius. Studia Antiqua Australiensia, 2. Turnhout 2006, 11-34. Zu den Collectanea ebd. 71-79.125.

28 Anastasii Bibl., ep. Iohanni diac.: MGH Epp. VII 442-426 (Perels/Laehr); NeIL, Popes (wie oben Fußnote 27), 148-161. Vgl. dazu G. LaEhr, Die Briefe und Prologe des Bibliothekars Anastasius. NA 47 (1928) 416-468, hier 437-441.

$29 \mathrm{Zu}$ dieser Frage s. unten Kap. 4.

30 Vgl. NeIL, Popes (wie oben Fußnote 27) 72-73.

31 Zur inhaltlichen Bedeutung dieser Auswahl von Texten s. unten S. 123-124.

32 Maximus Conf., Opusc. theol. et pol. 20 (PG 91, 228-245): PL 129, 568-574; WinKELMANn, Streit (wie oben Fußnote 1) Nr. 60; Jankowiak/Booth, A new date-list (wie oben Fußnote 15) Nr. 42.

33 Maximus Conf., Opusc. theol. et pol. 12 (PL 129, 573-576); WinkELMANN, Streit (wie oben Fußnote 1) Nr. 88; Jankowiak/Booth, A new date-list (wie oben Fußnote 15) Nr. 66.

34 Maximus Conf., Opusc. theol. et pol. 10 (PL 129, 577-578). Winkelmann, Streit (wie oben Fußnote 1) Nr. 93; Jankowiak/Booth, A new date-list (wie oben Fußnote 15) Nr. 43.

35 Theodorus I pp., ep. synodica Paulo Patr. Const. (PL 129, 577-582). WinkelmanN, Streit (wie oben Fußnote 1) Nr. 79. 
(6) Ein Brief desselben Papstes Theodorus I. von 643 an die Bischöfe, die Patriarch Paulos II.von Konstantinopel konsekriert hatten. ${ }^{36}$ Der Brief existiert nur in dieser Rückübersetzung.

(7) Einen Auszug aus einem Brief des Maximos Homologetes an den Abt Thalassios von 640 (CPG 7702). ${ }^{37}$ Der Text existiert nur in dieser Gestalt.

(8) Die Narrationes de exsilio Sancti papae Martini (BHL 5593-4). ${ }^{38}$

(9-15) Sechs Texte zu Leben, Prozess und Schicksal des Maximos Homologetes sowie dessen Testimonia et Syllogismi. ${ }^{39}$

Dass es sich bei allen Texten um Übersetzungen des Anastasius aus dem Griechischen handelt, ist bei den Briefen der Päpste (1.5.6) auffällig und bedeutet, dass der Bibliothecarius Romanae Ecclesiae diese Briefe nicht im päpstlichen Archiv gefunden hat. In seinem Brief an Iohannes Diaconus fällt die kryptische Bemerkung, dass ihm die Apologia Honorii nach seiner Übersetzung der Chronographia tripartita ${ }^{40}$ „in die Hände gefallen“ sei. ${ }^{41}$ Dass hier die Rückübersetzung aus dem Griechischen einer besonderen Begründung bedarf, hat Anastasius offensichtlich selbst empfunden. Denn im selben Brief bestätigt er ausdrücklich die Authentizität der Brieftexte, indem er argumentiert, dass die hinter dem griechischen Text festzustellende latina eloquentia es offensichtlich mache, dass die Briefe nicht auf Griechisch, sondern in lateinischer Sprache diktiert worden seien. ${ }^{42}$ Darüber hinaus verweist er auf ältere Präzedenzfälle, in denen päpstliche Briefe im lateinischen Original verlorengegangen seien und nur ex Graecorum post fonte librorum wiedergewonnen werden konnten. ${ }^{43}$ Mit dieser Argumentation ist

36 Theodorus I pp., ep. episcopis orient. (PL 129, 581-584). WinkELMANN, Streit (wie oben Fußnote 1) Nr. 81.

37 Maximus Conf., ep. Thalassio abb. (PL 129, 583-586). WinkELmann, Streit (wie oben Fußnote 1) Nr. 62; Jankowiak/Booth, A new date-list (wie oben Fußnote 15) Nr. 58.

38 Edition: NeIL, Popes (wie oben Fußnote 27) 166-233; Zur Narratio vgl. ebd. 95-103; WiNKELMANN, Streit (wie oben Fußnote 1) Nr. 138.

39 Ediert von: P. Allen / B. NeIL (Hrsg.), Scripta saeculi VII vitam Maximi Confessoris illustrantia, una cum latina interpretatione Anastasii Bibliothecarii iuxta posita. CCSG, 39. Turnhout/Leuven 1999. Zum Charakter dieser von den Herausgeberinnen „Documenta biographica“ genannten Quellen vgl. H. OHME, Maximos Homologetes (†662): Martyrium, Märtyrerbewusstsein, „Martyriumssucht"? ZAC 20 (2016) 306-346.

40 Vgl. dazu LaEhr, Briefe und Prologe (wie oben Fußnote 28) 432-435; NEIL, Popes (wie oben Fußnote 27) 66-67.

41 Anastasius Bibl., ep. Iohanni diac.: MGH Epp. VII 423, 33 (Perels/Laehr); NeIL, Popes (wie oben Fußnote 27) 150,15: ad manus nostras uenire contigit.

42 Anastasius Bibl., ep. Iohanni diac.: MGH Epp. VII 426, 1-3 (Perels/Laehr); NeIL, Popes (wie oben Fußnote 27) 160, 5-6.

43 Anastasius Bibl., ep. Iohanni diac.: MGH Epp. VII 426, 3-8 (Perels/Laehr); NeIL, Popes (wie oben Fußnote 27) 160, 6-14. Die beiden dafür genannten Beispiele sind (1.) ein Brief Papst Felix 
natürlich über die Authentizität der Textgestalt dieser Briefe nichts Abschließendes gesagt.

Daneben existiert eine arabische Überlieferung der Apologia Honorii in doppelter Gestalt. Eine bereits länger bekannte arabische Fassung bietet der Codex Vaticanus syriacus 130, fol.74r-84r in syrischer Schrift (karšūnī). Joseph Schacht hatte bereits im Jahre 1936 davon ein Faksimile mit deutscher Übersetzung und einer Einleitung publiziert. ${ }^{44}$ Ausweislich des Kolophon (fol. 218) wurde diese Handschrift im Jahre 1690 von dem Maroniten Yūḥannā ibn Zinda aus Aleppo geschrieben. ${ }^{45}$ Hubert Kaufhold verdanke ich die Auskunft, dass der Codex Aleppinus Metropolis Maronitarum Nr. 197 aus dem Jahre 1688 identischen Inhalts ist, aber nicht jene bei Anastasius Bibliothecarius überlieferten Textpassagen auslässt, die Schacht im Vaticanus syr. 130 festgestellt hatte. ${ }^{46}$ Diese Textlücken gehen also auf ein Versehen des Schreibers des Vaticanus zurück. Bei beiden maronitischen Codices handelt es sich um kanonistische Sammelhandschriften. Sie enthalten die sieben ökumenischen Synoden einschließlich des Quinisextums (691/92) sowie das Concilium Florentinum (1439) als „Achtes Ökumenisches Konzil“, weiterhin die altkirchlichen Lokalsynoden und von den Nomoi das sog. Syrisch-römische Rechtsbuch ${ }^{47}$ und den Procheiros Nomos von (870-879?) 907.48 Mit diesem Bestand an Kanones und Nomoi, inbesondere aber wegen des Quinisextums und der Nomoi handelt es sich um arabische melkitische Kanonessammlungen, die von den Maroniten übernommen und in konfessionsspezifischer Weise um das Florentinum ergänzt wurden, an dem sie teilgenommen hatten. Damit ist die ältere Ansicht hinfällig, die dem Schreiber des Vaticanus auch die materiale Zusammenstellung der Handschrift zum persönlichen Gebrauch

III. (483-492) mit dem Urteil gegen Petrus Fullo; (2.) das Vorwort Rufins zu den Ps.Clementinischen Rekognitionen an Gaudentius. Mit dem ersten ist wohl ep. 3, 4 oder 5 gemeint (PL 58, 904921); zu 2.vgl. Clementina, Recognitiones Rufino interprete, Prologus 2.8-9 (1-5, GCS 51 REHM/ PASCHKE).

44 J. Sснаснт, Der Briefwechsel zwischen Kaiser und Papst von 641/42 in arabischer Überlieferung. Orientalia N.S. 5 (1936) 229-268.

45 S. und J. Assemani, Bibliothecae Apostolicae Vaticanae Codicum Manuscriptorum Catalogus, Bd. III, Rom 1759, 192-196, hier 196; G. GRAF, Geschichte der christlichen arabischen Literatur, Bd. 3.Vatikan 1949, 381-382; H. KAUFHOLD, Sources of canon law in the Eastern churches, in W. Hartmann/K. Pennington (eds.), The history of Byzantine and Eastern canon law to 1500. Washington D.C. 2012, 215-342, hier 263.

46 Sснаснт, Briefwechsel (wie oben Fußnote 44) 240 Anm. 3, 243 Anm. 7, 245 Anm. 1. H. KAUFHOLD hat den Codex vor Jahren in Aleppo unter Autopsie beschrieben (schriftliche Mitteilung vom 16.2.2016).

47 W. Selb / H. KaUfHold, Das Syrisch-römische Rechtsbuch, 3 Bde. Wien 2002.

48 A. Schminck, Studien zu mittelbyzantinischen Rechtsbüchern. Frankfurt am Main 1986, 55-

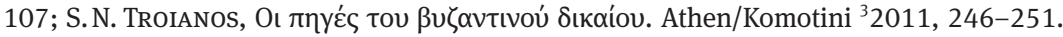


zugewiesen hatte. ${ }^{49}$ Die Apologia Honorii wird in diesen Handschriften in folgendem Kontext überliefert:

VI. Synodus sexta; I. Historia Synodi sextae; II. Epistola prima Johannis Papae ad Constantinum et Heraclium fratres Impp.; III. Eorundem Imperatorum Constantini et Heraclii Responsio ad Epistolam Iohannis Papae; IV. Epistola Theodori Papae ad Constantinum Imp.; V. Symbolum Synodi.

VII. Canones Trullani, sextae Synodo afficti, numero CII. ${ }^{50}$

Der Brief Papst Iohannes’ IV. wird hier also dem VI. Ökumenischen Konzil (680/81) und seinen Kanones zugeordnet, die allein in päpstlicher Tradition durch die Assemani-Brüder im Katalog mit einer eigenen Zählung als angeblich dem VI. Konzil „angedichtet“ davon abgetrennt werden, in der östlichen Tradition aber Kanones des VI. Konzils sind. ${ }^{51}$ Er wird weiterhin von einer kurzen historischen Einleitung zum III. Constantinopolitanum, dem Antwortschreiben der Kaiser ${ }^{52}$ an Papst Iohannes, sowie dem Schreiben Papst Theodorus I. an Kaiser Konstans II. ${ }^{53}$ und dem Horos („Symbolum“) der Synode begleitet.

M. Breydy hat 1983 darauf hingewiesen, dass derselbe Text wie im Vat. syr. 130 sich auch „dans les collections arabes melchites“ findet. Er nennt ff. Codices: Oxford Bodleianus arab. 36, Vaticanus arab. 150 und Vaticanus arab. 631, ${ }^{54}$ ohne ihnen weitere Beachtung zu schenken. Aus den Angaben des Kataloges von A. Nicoll $^{55}$ ergibt sich, dass der Cod. Bodl. arab. 36 zwischen 1398 und 1408 im Erzbistum Sinai entstanden ist. ${ }^{56}$ Es handelt sich ebenfalls um eine kanonistische

49 C. A. NALlino, Libri giuridici in versoni arabe cristiana die sec. XII-XIII. Rom 1925, 122; GRAF, Geschichte (wie oben Fußnote 45) 381-382. Diese Information verdanke ich H. KAUFHoLD, der diese Ansicht schon früher in Frage gestellt hatte.

50 Assemani, Catalogus (wie oben Fußnote 45) 194 (ff. 71v-116). Derselbe Inhalt steht im Aleppiner Codex auf den ff. 39v-77r.

51 H. Oнme (ed.), Concilium Constantinopolitanum a. 691/2 in Trullo habitum (Concilium Quinisextum), Acta Conciliorum Oecumenicorum, Series Secunda. Volumen Secundum, Pars Quarta. Berlin/Boston 2013, Einleitung LXIII-LXXIII.

52 DöLgER/MÜLleR, Regesten (wie oben Fußnote 7) Nr. 221. Die Angabe der Assemani-Brüder ist hier unzutreffend. Der Antwortbrief stammt von Kaiser Konstans II. S. unten Fußnote 82-85. 53 Winkelmann, Streit (wie oben Fußnote 1) Nr. 77.

54 M. BREYDy, Études sur Sa’ìd ibn Batrīq et ses sources. CSCO, 450 Subs. 69. Louvain 1983, 77 mit Anm. 5.

55 A. Nicoll, Bibliothecae Bodleianae Codicum Manuscriptorum Orientalium Catalogi II/1. Oxford 1821, 32-37.

56 Eine Inschrift auf fol. 3v eines Kleriker Markos des Erzbistums Sinai vom Jahre 1408 berichtet, dass der Codex dem Protos Fakhreddula gehört habe und jetzt „der Kirche unserer Herrin in der Stadt Kairo“ übergeben wurde. Die Hs. enthält eingangs die Narratio eines ägyptischen Presbyters 
Sammelhandschrift, die die sieben ökumenischen Synoden, die altkirchlichen Lokalsynoden, Väterkanones und Nomoi enthält. Zum VI. Ökumenischen Konzil meldet Nicoll:

27. Liber Epistolarum omnium Concilii sexti ex Oecumenicis (Cpolitani III), in quo Patres Episcopi ducenti octoginta novem contra Sergium et Cyrum congregati erant: fol. 206v.

28. Canones Concilii sexti Oecumenici numero CI. fol. $218 v^{57}$

Die Briefe stehen nach Breydy ${ }^{58}$ auf fol. 207r-218r, so dass davor die historische Einleitung stehen wird. Es handelt sich also abgesehen vom nicht enthaltenen Horos von 681 um eine sehr ähnliche Textzusammenstellung zum VI. Konzil in einem eindeutig melkitischen Codex.

Bei dem Vat. arab. 150 handelt es sich um einen Nomokanon der alexandrinischen koptischen Kirche aus dem Jahre 1332. ${ }^{59}$ Auf fol. 130 hat eine andere Hand iuxta arabicam Melchitarum editionem weitere Texte der ökumenischen Synoden III-VII hinzugefügt. ${ }^{60}$ Dies sind auf fol. 136-154:

4. Synodus sexta oecumenica, nempe constantinopolitana tertia, adversus Sergium et Pyrrhum, cui interfuere CCLXXXIX episcopi, a quibus conditi canones XCV. Inseruntur: 1. Epistola Iohannis patriarchae romani ad Constantinum et Heraclium imperatores. 2. Historia Cyri haeresiarchae. 3. Rescriptum Constantini imp. ad Iohannem papam. 4. Theodori patriarchae armenii epistola ad Constantinum imperatorem. 5. Symbolum fidei ad eadem synodo editum. ${ }^{61}$

Die aus melkitischer Tradition hier aufgenommenen Texte zum VI. Konzil sind identisch mit den o.g. Codices. Anscheinend hat der koptische Abschreiber die Kanones des Quinisextums mangels Bedarf weggelassen, obwohl sie in der Überschrift enthalten sind, ${ }^{62}$ und die historische Einleitung an die zweite Stelle

Joseph, der i.J. 1398 ordiniert wurde. Vgl. NicolL, Catalogi (wie oben Fußnote 55) 32 Anm. b; 33 mit Anm. a.

57 Ebd. 36. Die angegebene Teilnehmerzahl - wie häufig in der handschriftlichen Überlieferung - trifft nicht zu. Vgl. R. Riedinger, Die Präsenz- und Subskriptionslisten des VI. oekumenischen Konzils (680/1) und der Papyrus Vind.G.3. Abh. BAW philos.-histor. Klasse, NF 85. München 1979. Die Zählung der Kanones des Quinisextums schwankt häufig. Die Angabe „Epistolarum omnium concilii sexti“ ist nicht wörtlich zu nehmen.

58 BREYdy, Études (wie oben Fußnote 54) 77 Anm. 5.

59 A. MAI, Scriptorum Veterum Nova Collectio e Vaticanicis Codicibus edita IV. Rom 1831, 278 283. Auf fol. 128 steht ein Kopistenvermerk, der den Abschluss der Abschrift für 1332 bezeugt (ebd., 281).

60 MaI, Collectio IV (wie oben Fußnote 59), 282.

61 MaI, Collectio IV (wie oben Fußnote 59), 282.

62 Auch hier findet sich für das VI. Konzil dieselbe falsche Teilnehmerzahl wie im Bodl. arab. 36. Die falsche Zahl der Kanones des Quinisextums wird auf einem Schreibfehler der handschriftli- 
gerückt. Diese Tradition ist in weiteren arabischen melkitischen Handschriften enthalten. Dazu gehören der Cod. Vat. arab. $631,{ }^{63}$ der die genannten Texte auf fol.78r-91r enthält, ${ }^{64}$ und der Cod. Vat. Barberinianus orientalis 111 (a.1308). ${ }^{65}$ Es ist also festzuhalten, dass eine arabische Tradition der Apologia Honorii im Kontext kanonistischer Sammelhandschriften erfolgt ist. Sie begegnet in maronitischen, koptischen und melkitischen Handschriften, ist aber selbst melkitischer Herkunft. Ihr Merkmal ist, dass sie eingebunden ist in eine ergänzende Überlieferung von weiteren Texten zum VI. Ökumenischen Konzil, die sich ebenfalls auf Honorius beziehen, aber nicht zum Aktenbestand der Synode gehören.

Daneben existiert der Brief Papst Iohannes’ IV., die Antwort Kaiser Konstans' II. und der Brief Papst Theodorus' I. an Kaiser Konstans II. in einer ausführlich paraphrasierenden Form in den Annalen des melkitischen Patriarchen von Alexandrien, Eutychios (Sa’ìd ibn Batrīq; 877-940; sedit 933-940). ${ }^{66}$ Breydy hat die Annalen nach dem Codex Sinaiticus arab. 582 (s. X) ediert, den er für das Autograph des Eutychios hält, und mit einer deutschen Übersetzung versehen. Allerdings enthält dieser Codex nicht die genannten Texte zum VI. Konzil. Breydy nimmt deshalb an, dass die Texte zum VI. Konzil erst in der sog. ,antiochenischen Rezension“ der Annalen eingearbeitet wurden, als im 11. Jh. „Yahya ibn Sa’id das Werk umarbeitete und es in dem von den Byzantinern neu eroberten Antiochia im (sic!) Umlauf brachte. Es wurde immer mehr umgearbeitet, mit neuen Auszügen bereichert und handschriftlich vervielfacht. ${ }^{\text {"67 }}$ Diese Rezension findet sich in einer „unbegrenzten Zahl von Handschriften“ ${ }^{68}$ Eine kritische Ausgabe hat L. CHEIKHo

chen Tradition beruhen, zumal die Kanones selbst nicht überliefert werden. Die Bezeichnung von Papst Theodorus als ,armenischer Patriarch“ ist ein Kopistenfehler.

63 Über ihn lässt sich anhand von MAI, Collectio IV (wie oben Fußnote 59) 570 nur soviel sagen, dass es sich ebenfalls um eine kanonistische Sammelhandschrift handelt, die nur die Kanones der Synoden von Nicaea (315), Serdika (342), Ephesus (431), Konstantinopel (680/81) und Karthago enthält. Alle gehören zum Bestand griechischer Kanonessammlungen der byzantinischen Tradition. Vgl. H. OHME, Sources of the Greek canon law to the Quinisext Council (691/2): councils and church fathers, in HaRtmann/Penington, History (wie oben Fußnote 45) 24-114.

64 BREYDY, Études (wie oben Fußnote 54) 77 Anm. 5.

65 J.-B. DARBLADE, La collection canonique arabe des Melkites 13.-17.s. Fonti ser. II/13. Harissa (Libanon) 1946, 15-17.109. Diesen Hinweis verdanke ich H. Kaufhold.

66 M. BREYDY, Das Annalenwerk des Eutychios von Alexandrien. CSCO, 471/472. Scriptores arabici, 44.55. Louvain 1985, CSCO 471, VI; PmbZ Nr. 21977.

67 BREYDy, Études (wie oben Fußnote 54) 78; DERS., Annalenwerk (wie oben Fußnote 66) IX. Zu Yahya ibn Sa'id: PmbZ Nr. 28459.

68 BREYDY, Annalenwerk (wie oben Fußnote 66) beschreibt sie auf S. XIV-XXIII. Sie gehören alle ins 13. -18 . Jh. 
1909 vorgelegt. ${ }^{69}$ Alexander D. BEIHAMmERs Charaktisierung dieses Eutychiostextes der Apologia Honorii ist zuzustimmen: „Die arabische Fassung des Schreibens bei Eutychios läßt sich im Vergleich zur lateinischen Version als frei gestaltete und manchmal durch Interpolationen inhaltlich veränderte Kurzfassung des Volltextes charakterisieren, welche jedoch sowohl den Aufbau als auch einzelne Formulierungen des zugrundeliegenden Originals weiterhin klar erkennen lässt."70

J. SchAcHT ist bei seiner Analyse des Vat. syr. 130 und des Eutychiostextes der antiochenischen Rezension zu folgender Feststellung gelangt: „Die arabische Sprachform zeigt deutliche Spuren eines griechischen Originals.“ „Von einer syrischen Zwischenstufe ... sind keine sicheren Spuren aufgefallen. “"11 Beide Paralleltexte gehen nach ihm „zweifellos“ „auf eine gemeinsame arabische Quelle zurück“, die „nicht später als etwa 900 sein“ kann. ${ }^{72}$ Nach unseren bisherigen Beobachtungen zur Quellenlage kann man ergänzen, dass dies eine melkitische arabische Quelle war, in der eine im byzantinischen Kontext entstandene Ergänzung zum VI. Ökumenischen Konzil aus einer griechischen kanonistischen Sammelhandschrift ins Arabische übertragen wurde. Wann dies erfolgt ist, wird sich nicht mehr genau feststellen lassen. Jedenfalls muss die arabische Fassung bei der Umarbeitung der Annalen des Eutychios im zurückeroberten byzantinischen Antiochien des 11. Jh. bereits in der dortigen handschriftlichen melkitischen Tradition verankert gewesen sein.

Festzuhalten ist auch, dass es sich bei dieser handschriftlichen kanonistischen Tradition um ein außergewöhnliches Phänomen handelt, das anscheinend nur in der arabischen Überlieferung erhalten ist. Denn in der äußerst umfangreichen Überlieferung griechischer kanonistischer Handschriften ist diese Er-

69 L. CheIkн, Eutychii Patriarchae Alexandrini Annales I.II. CSCO, 50.51. Beyrouth 1906.1909; II, 28, 11 - 32,6. Eine deutsche Übersetzung dazu bietet Sснаснт, Briefwechsel (wie oben Fußnote 44) 252-257. Cheikнo hat seiner Edition die von E. Pocock erstellte lateinische Übersetzung der Erstausgabe (Oxford 1658/59) beigefügt, deren Abschnitt zum VI. Konzil sich in $P G$ 111, 1109 A-1110D findet.

70 A.D. BEIHAMmer, Nachrichten zum byzantinischen Urkundenwesen in arabischen Quellen (565-811). Poikila Byzantina, 17. Bonn 2000, 248. Zu Eutychios vgl. auch ebd. XXXIV-XXXIX. Bei seiner Kommentierung der drei o.g. Texte unter Reg. 204.232.233 berücksichtigt BeIHAMmER allerdings nur die antiochenische Rezension des Eutychios und Anastasius Bibliothecarius. Die kanonistische arabische Tradition kennt er nicht, selbst der von Sснаснт 1936 herausgegebene Vat. syr. 130 sei ihm „leider nicht einsehbar“ gewesen (ebd. 247). So sind BeIHAMmeRs Bemerkungen für unsere Untersuchung nicht weiterführend.

71 Sснаснт, Briefwechsel (wie oben Fußnote 44), 230.

72 Ebd. 233. 
gänzung zum VI. Konzil bislang nicht aufgetaucht. ${ }^{73}$ Man wird also sagen können, dass diese Ergänzungen nur in einem begrenzten Bereich byzantinischer kanonistischer Handschriften vorgenommen wurden. Damit steht die Frage im Raum, wann, wo und mit welchem Interesse dies erfolgt ist.

Von der Apologia Honorii Papst Iohannes' IV. existiert also weder das lateinische Original noch der griechische Text, der der Rückübersetzung des Anastasius Bibliothecarius zugrunde gelegen hat. Daneben existiert aber eine noch später entstandene arabische Überlieferung, in der Tat ein „,caso unico in tutta la storia papale.“74 Von dem Antwortschreiben Kaiser Konstans II. und dem Brief Papst Theodorus' an Konstans II. gibt es weder das jeweilige Original noch die jeweilige Übersetzung ins Griechische oder Lateinische, sondern allein die arabische Überlieferung in den genannten zwei Fassungen. Umso erstaunlicher ist es, dass die deutsche Übersetzung des arabischen Textes der Apologia Honorii im Vat. syr. 130 durch J. Sснаснт mit der lateinischen Rückübersetzung des Anastasius Bibliothecarius durchaus vergleichbar ist und erhebliche Sinnabweichungen kaum festzustellen sind.

\section{Der Text der Apologia Honorii Papst Iohannes' IV.}

Die auf den ersten Blick inhaltlich weitgehend übereinstimmenden drei Überlieferungsstränge der Apologia Honorii hat M. JANKOWIAK als „a coherent text“ bezeichnet, ${ }^{75}$ auf dessen Grundlage er dann seine o.g. These entwickelt und gleichzeitig in die Klage der inneren Widersprüche des Textes einstimmt. Wir werden im Folgenden die Authentizität des Textbestandes dieses Briefes prüfen, ohne allerdings in eine philologische Untersuchung des Wortlautes im engeren Sinne eintreten zu wollen. Dies muss einer von orientalistischer Seite zu erstellenden kritischen Edition vorbehalten bleiben. Für unsere Zwecke ist es ausreichend, den unterschiedlichen Textbestand anhand des Textes von Anastasius Bibliothecarius und der lateinischen und deutschen Übersetzungen der arabischen Traditionen zu erheben und nach den Ursachen der Unterschiede zu fragen.

73 Der Text des Concilium Quinsextum wurde für die kritische Edition z. B. in 218 Handschriften erfasst. Vgl. Онме, Concilium (wie oben Fußnote 51) Einleitung, IX-XVI.

74 P. ConTe, Il Sinodo Lateranense dell'ottobre 649. Collezione Teologica, 3. Vatikan 1989, 109. 75 JANKOWIAK, Invention (wie oben Fußnote 21), 339: „Luckily, these three different traditions yield a coherent text“. 
Fragt man nach dem äußeren Textbestand, so ist zu berücksichtigen, dass Anastasius Bibliothecarius bei etlichen Texten seiner Collectanea nur Exzerpte bietet. Neben den offensichtlichen Textauszügen bei den oben aufgelisteten ${ }^{76}$ Texten 2-4 und 7 sind von B. Neil auch die Papstbriefe der Collectanea in gleicher Weise als „Auszüge“ bezeichnet worden. ${ }^{77}$ Aus den Angaben des Anastasius Bibliothecarius lässt sich dies allerdings nicht erschließen. Denn Anastasius notiert in seinem Schreiben an Iohannes Diaconus ausdrücklich, bei welchen Texten es sich um Textauszüge handelt, eben bei den Texten $2-4$ und $7 .^{78}$ Bei der gemeinsamen Erwähnung der Papstbriefe tut er dies nicht. ${ }^{79}$ Und hinsichtlich des Briefes von Papst Iohannes IV. unterscheidet er sogar deutlich zwischen „der bereits erwähnten Apologie des Papstes Iohannes für Honorius“ und der „Apologie, die aus dem Brief des Maximos .... exzerpiert wurde“. ${ }^{80}$ Bei den Briefen des Theodorus fehlen offensichtlich Superscriptio und Subscriptio sowie das Prooemium, bei der lateinischen Fassung der Apologia Honorii nur Superscriptio und Subscriptio; ${ }^{81}$ in der arabischen Fassung ist auch die Superscriptio erhalten. ${ }^{82}$ Man wird also deutlich zwischen den nur fragmentarisch erhaltenen, weil von Anastasius Bibliothecarius exzerpierten, Texten und dem Textbestand der von ihm übersetzten Papstbriefe unterscheiden müssen.

Im Verlauf der Überlieferung im Abstand von Jahrhunderten zum Abfassungszeitpunkt ist es nun m. E. zu einer Fortschreibung dieser Texte gekommen. Ich will dies zuerst an dem Antwortschreiben Kaiser Konstans' II. an Papst Iohannes vom Sommer 642 in der Fassung des Vat. syr. 130 und bei Eutychios deutlich machen. ${ }^{83}$

76 S. oben S. 94-95.

77 Ohne nähere Begründung bezeichnet sie auch diese als „Extract“ A, E, F. Vgl. NEIL, Popes (wie oben Fußnote 27) 73-75.

78 Vgl. Anastasius Bibl., ep. Iohanni diac.: MGH Epp. VII 425, 12 - 13.19.19-21; 426,9-10 (Perels/Laehr); NeIl, Popes (wie oben Fußnote 27) 156, 24; 158, 7-10; 160,14-16.

79 Anastasius Bibl., ep. Iohanni diac.: MGH Epp.VII 425,31-426,1 (Perels/LaeHR); NeIL, Popes (wie oben Fußnote 27) 160,1-4.

80 Anastasius Bibl., ep. Iohanni diac.: MGH Epp. VII 425,11-13 (Perels/LaeHR); NeIL, Popes (wie oben Fußnote 27) 156,20-24: Sume igitur iam memoratam Iohannis papae pro Honorio apologiam, sume etiam et pro eodem ipso apologiam ex epistola Maximi ... diffloratam. " Gemeint ist opusc. theol. et pol. 20, s. oben Fußnote 17 und 32 (Collectanea Nr. 2).

81 So auch P. ConTE, Chiesa e primato nelle lettere dei papi del secolo VII. Mailand 1971, 427429 (Nr. 99).

82 Schacht, Briefwechsel (wie oben Fußnote 44) 235 (fol. 74aI).

83 Dölger/MülLER, Regesten (wie oben Fußnote 7) Nr. 221. Cod. Vat. syr. 30, fol. 80bII-82aII (Schacht 246-249); Eutychios, Annales (Cheikho II 31,5 -11; Schacht 256); Winkelmann, Streit (wie oben Fußnote 1) Nr. 75; Beihammer, Nachrichten (wie oben Fußnote 70) Reg. 232. 
Nach dem Vat. syr. 130 hat der Kaiser „die Darlegung deiner seligen Vaterschaft“ im „großen Rat“ in Anwesenheit des Patriarchen Paulos II. verlesen lassen. „Und wir alle freuen uns einmütig und anerkennen (sie) und glauben an sie ohne Meinungsverschiedenheit. “84 Der Patriarch habe bereits Schreiben gesandt, „die mit diesen deinen Worten übereinstimmen.“

Nun befehlen wir in unserem ganzen Reiche, dass in die Kirche keine Neuerung und keine unrichtige Ansicht eindringe ... Wenn aber etwas Unrichtiges und der Lehre der heiligen Väter Widersprechendes festgesetzt worden sein sollte, sei es die Häresie des Dekretes eines Königs oder in einer anderen Weise, in diesen vergangenen Jahren oder seit kurzer Zeit ..., so schaffen wir es aus unserem Reich ab und heben es auf. ${ }^{85}$

Diesen Worten kann man entnehmen, dass das päpstliche Schreiben eine Entfaltung der Christologie vorgenommen hat, der man in Konstantinopel zuzustimmen bereit war, was der Patriarch auch bereits brieflich bestätigt habe. Die kaiserliche Antwort bezeugt weiterhin ein Interesse am Konsens mit der römischen Kirche, das jede Neuerung - selbst wenn sie von kaiserlicher Seite formuliert worden sein sollte - zurückzunehmen bereit ist. Diese Bereitschaft wird allerdings deutlich konditioniert formuliert.

Bei Eutychios ist daraus Folgendes geworden:

Wir haben deine Ermahnung, o Heiliger, erhalten. Wir bekennen und glauben zwei Naturen, zwei Willen und zwei Tätigkeiten unseres Herrn und Messias, aber eine Person und verfluchen den, der davon abweicht. Wir glauben an das, was die 630 Bischöfe, die in der Stadt Chalkedon zusammengekommen sind, gesagt haben und verfluchen den, den sie verflucht haben. Wir haben uns nach deinem Befehl über die Verbrennung der Urkunde, in der Leo ... und die chalkedonische Synode angegriffen werden, gerichtet und sie mit Feuer verbrannt. Wir beharren auf deiner Lehre, die die Lehre der Wahrheit ist. ${ }^{86}$

Während in der ausführlichen Brieffassung im Vat. syr. 130 gar keine inhaltliche Angabe zu der Lehre des Papstes gemacht wird, der man einmütig zugestimmt habe, wird hier mit einer typischen späteren Kurzformel ${ }^{87}$ ein dyotheletisches und dyenergetisches Bekenntnis formuliert, wie es von der Lateransynode von 649 und

84 Deutsche Übersetzung: Schacht, Briefwechsel (wie oben Fußnote 44) 247.

85 Deutsche Übersetzung ebd. 248-249.

86 Deutsche Übersetzung ebd. 256; PG 111, 1111 A14-B12.

87 Vgl. z. B.: Vita Martini I. papae 13 (BHG 2259), 262 (Peters); Synopsis de haeresibus et synodis 24 (85, 37-38 Uthemann); Synodicon vetus 141 (118, 14 Duffy/PARKER); L. M. HoffMANN / W. BRANDES (Hrsg.), Eine unbekannte Konzilsynopse aus dem Ende des 9. Jahrhunderts. Forschungen zur byzantinischen Rechtsgeschichte, 30. Frankfurt/M. 2013, 174, 21-22. 
dann vom VI. Konzil formuliert wurde. In derselben Tradition wird dieses Bekenntnis als Bestätigung des Chalcedonense und des Tomus Leonis betrachtet und ohne jede Konditionierung die infrage stehende „Urkunde“ verbrannt. Damit liegt hier nicht einfach nur eine „Kurzfassung“ des kaiserlichen Briefes vor, sondern eine wesentlich Veränderung seines Inhaltes, die sich m. E. von daher erklärt, dass man sich in späterer Zeit eine Übereinstimmung in der Lehre mit dem Papst nur in Gestalt des dyotheletischen Dogmas von 680/81 vorstellen konnte einschließlich der auf dem VI. Konzil angeordneten Vernichtung aller monotheletischen Schriften. ${ }^{88}$ Festzuhalten bleibt, dass in dem authentischen Brief Papst Iohannes' IV. an Kaiser Konstans II. eine Christologie entfaltet wurde, der man in Konstantinopel meinte zustimmen zu können. Die überlieferte Textgestalt aber schließt dies - wie wir sehen werden - aus.

Eine Fortschreibung ist nun auch beim Text der Apologia Honorii zwischen der Fassung des Anastasius Bibliothecarius und dem Vat. syr. $130 \mathrm{zu}$ beobachten. J. Schacht hatte ohne jede inhaltliche Argumentation aus der Beobachtung, dass der Text des Vaticanus „ausführlicher“ sei als Anastasius, die Konsequenz gezogen, dass „es deutlich A(nastasius) (ist), der kürzt““ ${ }^{89}$ Dem ist nicht zuzustimmen. Man muss vielmehr jede einzelne Textdifferenz zwischen beiden Überlieferungen befragen, ob sich nachvollziehbare Gründe für Kürzungen oder Ergänzungen benennen lassen, um sich so der ursprünglichen Textgestalt anzunähern. Je ein Beispiel für eine Kürzung des Textes durch Anastasius Bibliothecarius und eine Ergänzung im Vaticanus soll dies verdeutlichen.

Eine Kürzung des Textes hat Anastasius Bibliothecarius m. E. am Anfang des Briefes vor der eingangs bereits zitierten ${ }^{90}$ Stelle vorgenommen, an der Iohannes auf die im Westen entstandene große Aufregung hinweist, die durch den Brief (litterae) des Pyrrhos und seine Inanspruchnahme des 1. Honoriusbriefes hervorgerufen wurde. Hier fehlt bei Anastasius folgende Textpassage:

Daher wünsche ich von euch, dass ihr die besten und vorzüglichsten Gebete zur Klärung dieses Zweifels aussprecht ....; denn hier ist eine Trübung vorgefallen, die geläutert werden muss, damit es die verständigen Leute, die darüber nachdenken, verstehen, sodass die Wahrheit wieder die Oberhand gewinnt, wie es anfänglich der Fall war. Ich habe nämlich die Meinungsverschiedenheit erfahren, die unter den Leuten des Westens herrscht, und die Zweifel, die zwischen ihnen vorgefallen sind. ${ }^{91}$

88 Auf der 13. Sitzung hat die Synode dies selbst durchgeführt: ACO ser. II 2, 2 p. 626, 11-19 (RIEDINGER).

89 Sснаснт, Briefwechsel (wie oben Fußnote 44) 231.

90 S. oben Fußnote 11.

91 Vat. syr. 130, fol. 74aII-bI; deutsche Übersetzung: SснAснт, Briefwechsel (wie oben Fußnote 44) 235-236. 
Die Freimütigkeit, mit der Iohannes hier über Meinungsverschiedenheiten „im Westen“ spricht - über die Position des Pyrrhos und wohl auch über die Berechtigung der Inanspruchnahme des Honoriusbriefes durch ihn -, scheint den noch darzustellenden Intentionen des Anastasius Bibliothecarius bei seiner Publikation der Apologia Honorii und der Collectanea nicht entsprochen zu haben. Er hat m.E. diese Passage deshalb einfach weggelassen.

Eine offensichtliche Ergänzung des Textes in der arabischen kanonistischen Tradition liegt m.E. am Ende des Briefes vor, wo Iohannes seine Forderungen gegen die von Pyrrhos öffentlich aufgehängte charta - gemeint ist die Ekthesis, ${ }^{92}$ zu deren Bestätigung er die oben erwähnte Synode durchgeführt hatte - formuliert. Der gemeinsame Text von Anastasius Bibliothecarius und dem Vat. syr. 130 lautet nach der lateinischen Fassung:

Wir haben erfahren, dass ein gewisses Dokument (charta quaedam) übergeben wurde, das die Priester zu unterschreiben gezwungen wurden und das gegen den Tomus des Papstes Leo seligen Angedenkens und die Synode von Chalcedon gerichtet ist. In diesem Dokument sind gewisse Neuerungen aufgestellt worden, die die kirchliche Lehre als vollständig zu widerlegen erkennt. (X)

Die göttliche Barmherzigkeit möge nun die Kaiser antreiben „,als Wächter unseres makellosen Glaubens“ diejenigen, die durch neue Erfindungen verdorben werden

durch kaiserliche Strafen (imperatoriis sanctionibus) abzuwehren und anzuordnen, dass jenes Dokument, das sich zu einem Ärgernis für den Glauben entwickelt und an öffentlichen Orten aushängt, abgenommen und zerrissen wird. ${ }^{93}$

An der von mir mit (X) markierten Stelle hat der Vaticanus zusätzlich folgende umfangreiche Passage:

92 So mit Winkelmann, Streit (wie oben Fußnote 1) Nr. 69 (S. 98); DöLGER/MÜLLER, Regesten (wie oben Fußnote 7) 97 (Reg. 221). Maximos Homologetes bezeichnet die Ekthesis und auch den

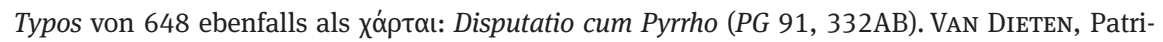
archen (wie oben Fußnote 1) 61 mit Anm. 11 wollte hier charta auf den Synodalbeschluss der Pyrrhos-Synode beziehen.

93 PL 129, 566 A11-B8: Comperimus autem quod charta quaedam mandata sit, in qua sacerdotes subscribere coacti sunt contra tomum beatae memoriae papae Leonis et Chalcedonensium synodum: in qua charta quaedam sunt per novitatem composita, quae dogma ecclesiasticum refutare omnino dignoscitur. (X) Inspiret ergo divina clementia Christianissimae pietati vestrae, et cum sitis custodes immaculatae fidei nostrae, vos ad compunctionem incitet, quo eos, qui novis sunt adinventionibus corrumpendi, imperatoribus sanctionibus arceatis, et praedictam chartam, quae in scandalum properat fidei, et locis publicis est suspensa, praecipiatis depositam scindi." Vat. syr. 130, fol. 79aI-bII: ScHACHT, Briefwechsel (wie oben Fußnote 44) 243-245. 
Denn man beabsichtigt damit eine Veränderung des wahren Glaubens, den der heilige Geist durch den Mund der Väter ausgesprochen hat. Nun möge euch die göttliche Barmherzigkeit ... eingeben ... und möge euch der göttliche Eifer antreiben, wie der durch die Gnade gekrönte Prophet David sagt, in dem er folgendermaßen spricht: ,Bin ich nicht gegen deine Widersacher, o Herr, zornig geworden und habe ich mich nicht im Grimm gegen deine Feinde aufgerieben' (Ps 139,21). Und ebenso hat der eifernde Prophet Elias in der Hitze seines Eifers zum Herrn gesagt: ,Mit Eifer habe ich geeifert für den Herrn Zebaoth, der das All überwacht; denn deine Propheten haben sie getötet, deine Altäre zerstört und deine Tempel niedergerissen. Ich allein bin übriggeblieben und auch nach meinem armen Leben haben sie getrachtet‘ (1Kön 19,10). Durch diesen Eifer hat er die falschen Propheten der Isebel getötet, durch diesen Eifer hat er die drei Heerführer des Königs Achab, die Anführer von Hundertschaften, getötet und die 150 Männer mit Feuer verbrannt, durch diesen Eifer hat er den Himmel verschlossen, das er keine Regen fallen liess und von ihm kein Tau auf das Antlitz der Erde herabkam. So geziemt es sich nun, dass man mit den Häretikern verfahre, die in der Kirche eine fremde Lehre und eine neue Gewohnheit lehren, ähnlich wie die Lehre der falschen Apostel, weil sie nach dem Untergang der Herde des Messias streben."94

Die in der arabischen Tradition überlieferte Fortschreibung des Textes hat die „göttliche Barmherzigkeit“ mit dem „göttlichen Eifer“ als Motiv geforderten kaiserlichen Handelns ergänzt und das Motiv des Eifers vor allem am Beispiel des Propheten Elia zum Handlungsmuster erhoben. Dadurch ist eine deutliche Verschärfung in der päpstlichen Forderung erfolgt. Während der lateinische Text fordert, durch Strafen die „Neuerer“ abzuwehren, das Dokument abzunehmen und außer Kraft zu setzen, unterstellt der Text des Vaticanums eine absichtliche Verfälschung des Glaubens, bringt die Bezeichnung „Häretiker“ ins Spiel und fordert deren physische Vernichtung nach dem Beispiel der Propheten Isebels. Diese Radikalisierung in der Tonlage setzt eine Entwicklung voraus, die sich erst in den Briefen und Maßnahmen der Nachfolger von Iohannes IV., Theodorus I. (642649) ${ }^{95}$ und Martin I. (649-653) ${ }^{96}$ feststellen lässt, die zur Lateransynode von 649 und deren Anathematismen ${ }^{97}$ geführt haben. Sie ist jedoch nicht vorstellbar im Kontext dieses ersten päpstlichen Protestes gegen die konstantinopolitanische Religionspolitik. Vor allen Dingen aber ist sie völlig inkompatibel mit der eingangs von Iohannes benutzten Anrede des Pyrrhos als ,unser Bruder Patriarch Pyrrhos “98 und der Bezeichnung des Sergios als reverendae memoriae patriarcha. ${ }^{99}$

94 Vat. syr. 130, fol. 79aII-bI; deutsche Übersetzung: ScHAcHт, ebd. 244.

95 PmbZ Nr. 7769.

96 PmbZ Nr. 4851.

97 Concilium Lateranense a. 649: ACO ser. II 2,1 p. 364, 15 - 388, 31. Vgl. auch PRICE, Lateran Synod (wie oben Fußnote 25) 375-384.

98 Iohannes IV., ep. Constantino Imp.: PL 129, 561D1. Bezeichnenderweise hat hier der Vaticanus - unsinnigerweise - den Namen Pyrrhos durch Johannes ersetzt: fol. 74bI (SсHACHT 236). 99 Iohannes IV., ep. Constantino Imp.: PL 129, 562C4. 
Wie ist nun aber die Widersprüchlichkeit in der theologischen Argumentation der Apologia Honorii zu beurteilen, die im Wesentlichen sowohl bei Anastasius als auch in der arabischen Tradition übereinstimmend überliefert ist? Dazu wird im Folgenden diese Argumentation in ihren zentralen Aussagen strukturell erschlossen, um von daher nach ihrer Authentizität zu fragen.

Der Brief Iohannes' IV. bietet nach eine kurzen Proömium ${ }^{100}$ und der oben diskutierten Entfaltung seines Anlasses ${ }^{101}$ einen längeren theologischen Gedankengang, mit dem die als problematisch betrachtete Aussage des 1. Honoriusbriefes über den einen Willen Christi einer ,authentischen“ Interpretation unterzogen wird. ${ }^{102}$ Dieser Gedankengang lässt sich folgendermaßen strukturieren: $<1>^{103}$ Hororius wurde von Sergios unterrichtet, dass gesagt werde, in Christus gäbe es zwei entgegengesetzte Willen. Honorius habe darauf geantwortet, dass Christus einer sei (sicut esset monadicus unus), vollkommener Gott und Mensch, uns in allem gleich. Er habe einen menschlichen Leib und eine Vernunftseele angenommen, aber ohne Sünde, ,und wollte deshalb einen Willen seiner menschlichen Natur entsprechend der ursprünglichen Bildung der Natur Adams haben. “104

$\langle 2\rangle^{105}$ Christus habe nicht zwei entgegengesetzte Willen gehabt wie wir sie haben, den einen im Fleisch, den anderen im Geist; ausführlich Begründung mit Röm 5,14; Gal 5,17; Ijob 14,4(LXX); Ps 51,7; 1Kor 15,22; Röm 5,19. Weil Christus der einzige Mittler ohne Sünde ist, war auch in seinem Wirken kein Gegensatz zwischen zwei Willen des Fleisches und des Geistes, sondern ein einheitlicher menschlicher Wille. In diesem Sinn habe Honorius dem Sergios geschrieben (Verweis auf Röm 7,18-20,23).

$<3\rangle^{106}$ „Aber niemand von geringerer Einsicht möge den Vorwurf erheben, warum nur über die menschliche Natur, nicht aber auch über die göttliche Natur zu lehren gewusst wurde, wird Christus doch in zwei in einer Person vereinten Naturen erkannt, angebetet und als vollkommener Gott und Mensch verehrt. Wer darüber streitet, muss jedoch wissen, dass sich die Antwort auf die Anfrage des

100 Iohannes IV., ep. Constantino Imp.: PL 129, 561C1-13; Vat. syr. 130, fol. 74aI-II (ScHACHT 235).

101 Iohannes IV., ep. Constantino Imp.: PL 129, 561C13-562C6; Vat. syr. 130, fol. 74aII-75aI (ScHACHT 235-236).

102 Iohannes IV., ep. Constantino Imp.: PL 129, 562C6-565 C12; Vat. syr. 130, fol. 75aI-78bI (SCHACHT 235-242).

103 PL 129, 562C4-563 A8; Vat. syr. 130, fol. 75aI-bII (Сснаснт 236-237).

104 PL 129, 563 A6-8: et idcirco unam voluntatem secundum primam formationem Adae naturalem humanitatis suae Dominus Jesus Christus habere dignatus est.

105 PL 129, 563 A9-564 B1; Vat. syr. 130, fol. 75bII-77aI (Sснаснт 236-240).

106 PL 129, 564B1-D7; Vat. syr. 130, fol. 77aI-bI (Sснаснт 240-241). 
bereits erwähnten Patriarchen bezog. “107 Denn auch der Apostel Paulus pflegte sich dem jeweiligen Verständnis seiner Zuhörer klug anzupassen (audientibus semet configurat sapienter) und jeweils entweder nur von der Gottheit, dann wieder nur von der menschlichen Natur Christi zu reden; ausführliche Begründung anhand 1Kor 1,24-25.

$\langle 4\rangle^{108}$ Nur wir haben zwei entgegengesetzte Willen: ausführliche Begründung mit Eph 2,1-3; Röm 7,25. „Unser Herr aber wollte einen natürlichen menschlichen Willen annehmen, welchen er in seinem eigenen Fleisch bewegte indem er damit seine Macht als Herr aller demonstrierte, weil ihm doch alles als Gott zu Diensten steht! Und wirklich kannte er keine Sünde, fügte auch keine (Sünde) aus Pflichtverletzung hinzu, weil er allein ohne Sünde und das Vergehen der Pflichtverletzung geboren wurde.“109

$\langle 5\rangle^{110}$ „Unser erwähnter Vorgänger lehrte also über das Geheimnis der Menschwerdung Christi, dass in ihm nicht wie bei uns Sündern entgegengesetzte Willen des Geistes und Fleisches existierten. Das haben einige in ihre eigene Ansicht verdreht und geargwöhnt, dass er einen Willen seiner Gotheit und Menschheit gelehrt habe, was der Wahrheit in jeder Hinsicht entgegengesetzt ist. "111

Diese lange Textsequenz unternimmt den Versuch, die Aussage des Honorius von dem einen Willen Christi allein auf dessen menschliche Natur zu beziehen, die im Unterschied zum Menschen unter der Sünde nicht durch einen sich selbst widerstrebenden und insofern entzweiten Willen gekennzeichnet ist. Die dazu herangezogene Lehre von der Annahme der menschlichen Natur, wie sie schöpfungsgemäß vor dem Fall Adams konstituiert war, ist traditionell. Bemerkenswert ist die Betonung der Einheit der Person als Begründung für die Einheit seines Willens in Textsequenz $<1>$ und $<2>$. Ebenso bemerkenswert ist die in $<4>$ vorge-

107 PL 129, 564B1-8: Sed ne quis nonnumquam minus intelligens reprehendat, quamobrem de humana tantum natura, et non etiam de divina natura docere sciatur: etenim Christus in duabus naturis in una persona unitis cognoscitur, adoratur, et colitur Deus et homo perfectus. Debet qui super hoc ambigit scire, quoniam ad hoc facta est responsio ad jam dicti patriarchae interrogationem. 108 PL 129, 564D8-565 C5; Vat. syr. 130, fol. 77bI-78aII (Sснаснт 241-242).

109 PL 129, 565B14-C5: Dominus autem noster unam voluntatem humanitatis naturalem suscipere dignatus est, quam in propria carne potestative ut omnium Dominus circumferebat, eo quod omnia serviant Deo: nullum profecto habens vel afferens ex praevaricatione peccatum, quoniam solus sine peccato et crimine praevaricationis est natus."

110 PL 129, 565C6-12; Vat. syr. 130, fol. 78aII (SснасHт 242).

111 PL 129, 565C6-12: Praedictus ergo decessor mens docens de mysterio incarnationis Christi dicebat, non fuisse in eo, sicut in nobis peccatoribus, mentis et carnis contrarias voluntates. Quod quidam ad proprium sensum convertentes, divinitatis ejus et humanitatis unam eum voluntatem docuisse suspicati sunt, quod veritati omnimodis est contrarium.“ 
nommene Begründung der mit sich selbst nicht im Widerspruch stehenden Einheitlichkeit des menschlichen Willens Christi von der potestas seiner Gottheit her, der alles zu Diensten steht und durch die es die eine Person Christi ist, die in dem angenommenen Fleisch den einen menschlichen Willen bewegt. Damit wird die Willenseinheit des Menschen Jesus hier nicht von der Natur, sondern von der Person her begründet. Dies ein Ansatz, der durchaus dem monotheletischen Denken entgegenkam. Schließlich ist auffällig, dass der Verfasser sich darüber im Klaren ist, dass diese Interpretation des Honoriusbriefes die Frage aufwerfen muss, warum denn nichts von der göttlichen Natur gesagt werde. Es wird deshalb in Textsequenz $<3>$ der Versuch unternommen, die Argumentation des Honorius in Analogie zur Redeweise des Apostel Paulus als situativ bestimmt zu erklären. Die Interpretation der Aussage von dem einen Willen Christi auf beide Naturen sei eine - jetzt durch Pyrrhos erfolgte - Verdrehung dessen, was Honorius gedacht habe, weil es der Wahrheit widerspreche $<5>$.

Damit bietet der Brief auf nicht weniger als 3 Spalten in der Edition der Patrologia Latina einen in sich durchaus kohärenten theologischen Gedankengang, der die aktuelle Problemlage durchscheinen lässt, auf potentielle Einwände einzugehen bereit ist und vom Ansatz her Verständigungspotential in sich birgt. Dass damit die Aussage des Honoriusbriefes falsch interpretiert wird, steht auf einem anderen Blatt. ${ }^{112}$ Überdies schlösse sich die oben diskutierte Schlusspassage ${ }^{113}$ mit den Forderungen zur Ekthesis hier nahtlos an. Der gemeinsame Text bei Anastasius und im Vaticanus bietet nun aber zuvor noch folgende Argumentation.

$\langle 6\rangle^{114}$,Aber ich verlange doch, dass sie dem Fragenden antworten, in Bezug auf welche Natur sie sagen, dass Christus Gott einen Willen habe. " ${ }^{115}$ Gehöre er zur göttlichen Natur, sei Manichäismus die Folge; gehöre er zur Menschheit Adoptianismus (genannt werden Photeinos und „Ebion“). „Wenn sie aber wirklich behauptet haben, dass ein Wille aus beiden Naturen bestehe, werden sie nicht nur die naturhaften Willen (naturales voluntates), sondern die Naturen selbst vermengen, so dass weder dieses noch jenes, also das Göttliche und das Menschliche, erkannt werden könne. "116 Auch wenn gegen Nestorios keine Trennung der Naturen geduldet wird, sind sie doch $\mathrm{zu}$ unterscheiden und nicht $\mathrm{zu}$ vermischen. „Weil sie nämlich einen Willen und eine Wirkweise der Gottheit und Menschheit

112 Vgl. KreuZER, Honoriusfrage (wie oben Fußnote 2) 17-58. 60-64.

113 S. oben Fußnote 93.

114 Iohannes IV., ep. Constantino Imp.: PL 129, 565C12-566 A10; Vat. syr. 130, fol. 78bI-79aI (SCHACHT 242-243).

115 PL 129, 565C12-14: Verumtamen vellem, ut interroganti responderent, secundum quam naturam dicunt Christi Dei unam voluntatem?

116 PL 129, 565D5-9. 
lehren: was ist das anderes, als dass sie als solche erkannt werden, die auch eine Natur von Christus Gott gemäß der eutychianischen und severianischen Einteilung lehren? Überhaupt aber bestimmen die orthodoxen Väter ... in übereinstimmender Verkündigung, so wie beide Naturen auch beide Willen und Wirkweisen Christi zu lehren." ${ }^{117}$

In dieser Textsequenz $\langle 6\rangle$ wird mit einer rhetorischen Frage nun zusätzlich eine Destruktion der vermeintlichen Position des sich auf Honorius berufenden Pyrrhos unternommen. Dabei wird das grundlegende Argument aus einem ontologischen Begriff der Natur des Menschen gewonnen, zu der per definitionem auch das Willensvermögen und das Handlungsvermögen gehören sollen. Insofern wird hier den beiden Naturen Christi je ein „naturhafter“ Wille (und implizit auch eine „naturhafte“ Wirkweise) zugeordnet, so dass sich in reziproker Weise Wille/ Wirkweise und Natur entsprechen. Daraus ergibt sich dann das scheinbar logische Argument, dass aus der Lehre des einen Willens Christi zwangsläufig auch der Monophysitismus des Eutyches und Severus folge. Damit aber sind die ontologischen Prämissen des maximianischen Dyotheletismus und Dyenergismus, wie sie in etwa in der Disputatio cum Pyrrho ${ }^{118}$ durch Maximos entfaltet werden und die Argumentation der Lateransynode bestimmt haben, ${ }^{119}$ bereits Papst Iohannes IV. zugewiesen worden.

Verstärkt wird diese Zuweisung durch eine weitere Textpassage, die allerdings bei Anastasius Bibliothecarius fehlt und nur in der arabisch-kanonistischen Tradition der Apologia Honorii enthalten ist. Dort steht noch vor den Teilen $\langle 1\rangle-\langle 6\rangle$ folgender Text:

$<0>$ Kyros von Alexandrien habe „über Jesus eine Behauptung neu aufgestellt, die unsere vergangenen Väter nicht gekannt haben. Er behauptete nämlich, dass er einen Willen und eine Wirksamkeit hätte. " Sergios habe dies Honorius mitgeteilt. „Da lehnte er es ab, missbilligte es aufs äußerste und sagte zu ihm: Diese

117 PL 129, 566 A3-10: Quia enim unam voluntatem dicunt divinitatis Christi et humanitatis, et unam simul operationem: quid aliud, nisi quia et unam naturam Christi Dei secundum Eutychianam et Serverianam divisionem operari noscuntur? Denique orthodoxi Patres ... sicut utrasque naturas, ita et voluntates ac operationes Christi docere concordi praedicatione monstantur. C. CUBITT in Price, Lateran Synod of 649 (wie oben Fußnote 25) 49 mit Anm. 139 behauptet irrtümlich, dass in der lateinischen Übersetzung des Anastasius Bibliothecarius ,an explicit statement of ,two wills and two operations“" fehle.

118 Disputatio Maximi Conf. cum Pyrrho: $P G$ 91, 287-353. Zur Entwicklung des Dyotheletismus

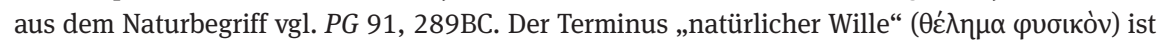
genuin maximianisch. Vgl. z.B. $P G$ 91, 301BC.

119 Zum Schlussverfahren von einem Willen / einer Wirksamkeit auf eine Natur vgl. z. B. die Eröffnungsrede Papst Martins auf der Lateransynode von 649: ACO ser. II 2,1 p. 12, 19-14, 9 (RIEDINGER). 
Behauptung ist eine, die von der Ansicht der Kirche abweicht.“ Richtig sei vielmehr, dass Christus „zwei Willen und zwei Wirkweisen hat, wie er auch zwei Naturen hatte; denn es ist unmöglich, dass ein Besitzer von zwei Naturen einen Willen habe. Wenn er also einen Willen hätte, hätte er eine Natur. Da er aber zwei Naturen hat, hat er zwei Willen. “120

Hier wird historisch falsch behauptet, dass in der Unionsurkunde ${ }^{121}$ der Union zwischen den ägyptischen Theodosianern und dem chalcedonensischen Patriarchen von Alexandrien, Kyros, im Jahre 633 bereits von einem Willen die Rede gewesen sei. Dieses Dokument ist bekanntlich allein Ausgangspunkt der Kon-

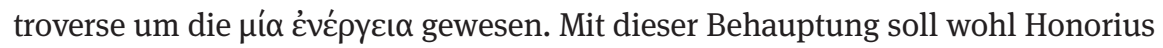
zusätzlich entlastet werden. Man darf jedoch annehmen, dass im Jahre 641 das Wissen über den tatsächlichen Inhalt der Unionsurkunde noch vorhanden war, so dass schon deshalb diese Passage anachronistisch ist. Das folgende angebliche dyotheletische Bekenntnis des Honorius rahmt nun gleichsam mit Teil $\langle 6\rangle$ die Argumentation der Teile $<1>-<5>$.

Es ist m.E. aus mehreren Gründen zu bezweifeln, dass die Teile $\langle 6\rangle$ und $<0>$ zum authentischen Bestand der Apologia Honorii gehören. Zum einen entsteht damit der bereits erwähnte ${ }^{122}$ und schon früher beobachtete und beklagte argumentative Widerspruch im Gedankengang des Briefes, der die innere Einheit des Textes zerstört. Denn es ist schlecht möglich zu argumentieren, dass Honorius die Aussage von zwei Willen in Christus abgelehnt habe und sie nur für die Natur des Menschen unter der Sünde möglich gehalten habe, um sie dann wieder auf die göttliche und menschliche Natur Christi zu beziehen. Vor allen Dingen aber macht eine Inhaltsangabe der Apologia Honorii, die Maximos Homologetes während der im Jahre 645 in Karthago durchgeführten Disputatio cum Pyrrho gab, deutlich, dass es sich bei den Teilen $\langle 6\rangle$ und $\langle 0\rangle$ um spätere Interpolationen handeln muss. Von Pyrrhos in Karthago auf den Honoriusbrief angesprochen, erklärte Maximos, dass die Interpretation des Honoriusbriefes durch die Apologia Honorii deshalb größere Glaubwürdigkeit genieße als dessen monotheletische Inanspruchnahme, weil beide Briefe vom selben Diktatgeber ${ }^{123}$ verfasste worden seien, der noch am Leben

120 Vat. syr. 130, fol. 74bII-75aI; deutsche Übersetzung: ScHACHт, Briefwechsel (wie oben Fußnote 44) 236.

121 Concilium Constantinopolitanum a. 680/1, ACO ser. II 2,2 p. 594, 17 - 600, 20; vgl. WiNKELMANN, Streit (wie oben Fußnote 1) Nr. 27. Zu dieser Union vgl. LANGE, Mia energeia (wie oben Fußnote 4) 575-581.

122 S. oben S. $92-93$.

123 Nämlich von dem römischen Abt Iohannes, der den Honoriusbrief in lateinischer Sprache verfasst habe. Dies berichtet Maximos in seinem Brief an den zyprischen Presbyter Marinos ( $P G$ 91, 228B-245D. 244C-245 A = PL 129, 571CD = Anastasius Bibl., Collectanea Nr. 2, s. oben 
sei. ${ }^{124}$ In diesem Zusammenhang nimmt Maximos folgende paraphrasierende Inhaltsangabe vor:

„Dieser (sc. der römische Abt Iohannes) sagte nun (in einem Schreiben) an den heiligen Konstantinos, den damaligen Kaiser, das er im Auftrag des inzwischen unter den Heiligen weilenden Papstes Iohannes abfasste, über diesen Brief:

(1) ,Einen einzigen Willen im Herrn haben wir behauptet, jedoch nicht seiner Gottheit und Menschheit zugleich, sondern allein seiner Menschheit. Nachdem nämlich Sergios geschrieben hatte, manche würden zwei einander widersprechende Willen in Christus behaupten, haben wir dagegen geschrieben, Christus habe nicht zwei einander widersprechende Willen gehabt, nämlich einen des Fleisches und einen des Geistes, wie wir sie haben nach dem Sündenfall, sondern einen einzigen, der seine Menschheit naturgemäß charak-

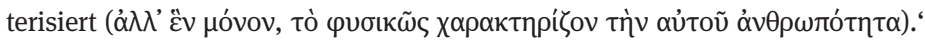

(2) Und ein evidenter Beweis dafür ist, dass sowohl die Glieder als auch das Fleisch erwähnt werden, was unmöglich auch auf seine Gottheit bezogen werden kann.

(3) Dann sagte er auch und nimmt damit einen möglichen Einwand vorweg: ,Wenn aber jemand sagen wollte: Weswegen habt ihr, als ihr über die Menschheit Christi gehandelt habt, seine Gottheit nicht erwähnt? Dann sagen wir, dass wir erstens auf die Anfrage geantwortet haben, zweitens aber, wie in allem, so auch in diesem Punkt der Gewohnheit der Schrift folgen, die einmal von seiner Gottheit handelt, so wenn der Apostel sagt: ,Christus ist Gottes Kraft und Gottes Weisheit' (1Kor 1,24), ein andermal aber von seiner Menschheit, und nur von ihr, so wenn derselbe sagt: ,Die Torheit Gottes ist weiser als die Menschen, und die Schwachheit Gottes ist stärker als die Menschen' $(1$ Kor 1,25$){ }^{125}$

Fußnote 32). Der Schüler des Maximos, Anastasios Monachos (PmbZ Nr. 237), sei in Rom gewesen

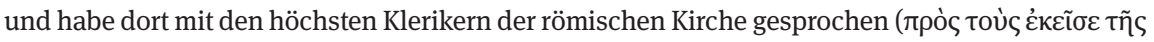

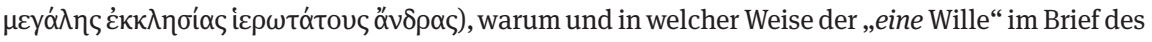
Honorius an Sergios eingefügt worden sei. Er habe sie deswegen ungehalten und sich selbst

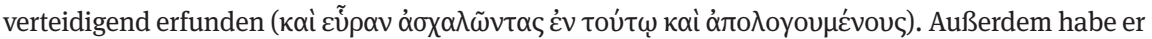
auch mit dem Abt Iohannes gesprochen, der den Brief auf Latein diktiert habe, und der darauf bestanden habe, dass nirgends in diesem Brief im numerischen Sinne von einem Willen die Rede sei; dies sei vielmehr von denen erdichtet worden, die den Brief ins Griechische übersetzt hätten. „Diese Antwort des Abtes Johannes ist eine bewußte Verdrehung der Tatsachen“ (G. KREUzER, Honoriusfrage, wie oben Fußnote 2, 63). Man fragt sich, warum der römische Abt nicht einfach die Kopie des lateinischen Originals, die zu diesem Zeitpunkt doch noch existiert haben muss, dem Anastasios Monachos gezeigt hat, der zweisprachig war!

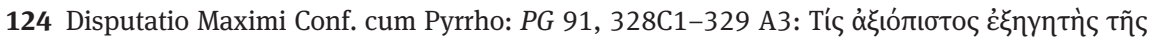

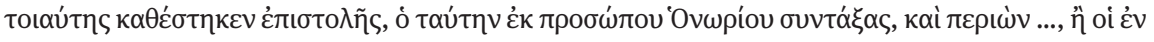

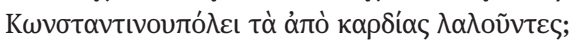

125 Disputatio Maximi Conf. cum Pyrrho: PG 91, 329 A5-C2; die deutsche Übersetzung wurde mit geringen Veränderungen übernommen von G. BAUSENHART, „In allem uns gleich außer der Sünde“. Studien zum Beitrag Maximos’ des Bekenners zur altkirchlichen Christologie. Tübinger Studien zur Theologie und Philosophie, 5. Mainz 1990, 220-221. 
Diese paraphrasierende Inhaltsangabe der Apologia Honorii durch Maximos ist erstaunlich präzise. Teil (1) entspricht den Textsequenzen $\langle 1\rangle,\langle 2\rangle$ und $\langle 5\rangle$ der Apologie, Teil (3) paraphrasiert Sequenz <3> der Apologie. Auffällig ist, dass die Argumente zu den Einwänden gegen die Interpretation des Honoriusbriefes genau aufgelistet werden. Besonders hervorzuheben ist aber, dass die im jetzigen Textbestand der Apologia Honorii hinzugefügte ontologische Argumentation mit dem Naturbegriff $<6>$ in der Paraphrase des Maximos völlig fehlt! Wäre sie authentisch, hätte er einen Hinweis darauf gewiss nicht versäumt, zumal seine Apologie des Honoriusbriefes vom Jahre 641 in dem Brief an den zyprischen Presbyter Marinos (Opusculum 20), die Anastasius Bibliothecarius in seine Collectanea aufgenommen hat, ${ }^{126}$ den Nachweis bringen will, dass die Theologie des Honorius keine Verleugnung der Zweiheit der naturhaften Willen impliziere, sondern sie geradezu voraussetze. ${ }^{127}$ Das Fehlen dieses Argumentes in der Inhaltangabe der Disputatio cum Pyrrho ist auch deshalb bedeutsam, weil diese mit großer Wahrscheinlichkeit erst zwischen 655 und 662 von den engsten Anhängern des Maximos - möglicherweise sogar unter dessen Beteiligung während seines Exils - verfasst worden ist. ${ }^{128}$ Das bedeutet, dass der oder die Verfasser der Disputatio noch ca. 15-20 Jahre nach der Abfassung der Apologia Honorii über deren Argumentation genaue Kenntnisse hatten. M.E. muss man daraus sogar schließen, dass ihnen der Text zur Verfügung stand. Ebenso sind hier auch detaillierte Kenntnisse des 1. Honoriusbriefes festzustellen, denn das mit der Bemerkung von Maximos eingeschobene Argument von Sequenz (2) bezieht sich ja auf den Text der Honoriusbriefes, in dem in der Tat an einer einzigen Stelle in Aufnahme von Röm 7,23.25 von Christus gesagt wird: „Ein anderes Gesetz oder ein verschiedener oder entgegengesetzter Wille war nämlich nicht in den Gliedern des Erlösers, weil er jenseits des Gesetzes der menschlichen Natur geboren wurde. "129 Maximos hatte bereits in seiner eben erwähnten Apologie des Honoriusbriefes u.a. auch diese Stelle des Honoriusbriefes zitiert und interpretiert. ${ }^{130}$ Die Apologie Papst Iohannes' IV. bezieht sich zwar ebenfalls auf Röm 7, 23, argumentiert dann aber nicht mit Natur und

126 Als zweiten Text, s. oben Fußnote 32.

127 Maximus Conf., Opusculum 20 (PG 91, 237C10-D5 = PL 129, 567 A1-9).

128 Vgl. J. NoRet, La rédaction de la Disputatio cum Pyrrho (CPG 7698) de Saint Maxime le Confesseur serait-elle postérieure à 655? Analecta Bollandiana 117 (1999) 291-296.

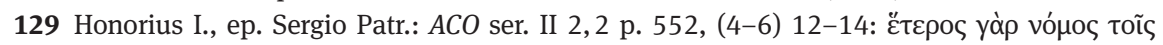

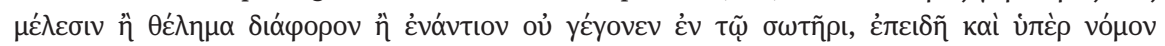

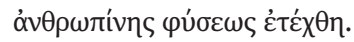

130 Maximus Conf., Opusculum 20 (PG 91, 241B5-13 = PL 129, 569B13-C6). 
Gliedern Christi. ${ }^{131}$ Was bedeutet es, dass Maximos und die Maximianer noch zwischen 655 und 662 bestens über diese beiden Texte im Bilde sind?

Ich fasse zusammen. Wir haben bei unserer Textanalyse festgestellt, dass es sich im überlieferten Textbestand der Apologia Honorii nicht um einen inhaltlich kohärenten Text handelt. Dieser erstmals im Jahre 874/75 literarisch bezeugte Brief ist in seiner Überlieferung zwischen 641 und 874/75 und danach offensichtlich mehrfach einer Fortschreibung unterzogen worden. Es sind dem Text Passagen zugewachsen, die im Widerspruch zu Formulierungen desselben Briefes stehen. Diese Passagen sind historisch anachronistisch und falsch und führen die innere theologische Argumentation ad absurdum. Um diese Entwicklung zu verstehen, ist es nicht nötig, die logische oder theologische Kompetenz des Verfassers in Frage zu stellen oder den abendländischen Bildungsabsturz im 7. Jh. zu bemühen. Vielmehr bleibt zu klären, warum dies erfolgt ist. Es hat anscheinend mehrfach ein Interesse an der eindeutigen Orthodoxie des Honorius und einer durch nichts in Frage zu stellenden Rechtgläubigkeit der römischen Kirche gegeben. Dabei wurde Rechtgläubigkeit im Sinne der dogmatischen Entscheidungen der Lateransynode von 649 und des VI. Ökumenischen Konzils verstanden und in diesem Sinne die Apologia Honorii angepasst. Als Ansatzpunkt für die Klärung der Ursachen und der historischen Kontexte bietet sich die Frage an, warum eigentlich Anastasius Bibliothecarius die Apologia Honorii in seine Collectanea eingefügt hat. Und warum findet sich dieser Text in einem Teil der byzantinischen kanonistischen Tradition im Zusammenhang der VI. Ökumenischen Konzils? Zuvor ist aber ein Blick auf die Überlieferung der von Iohannes IV. durchgeführten Synode zu werfen.

\section{Die römische Synode Papst Iohannes' IV.}

Theophanes Confessor (759/60-818) ${ }^{132}$ berichtet in seiner Chronographia unter AM 6121 nach dem Tod des Herakleios und dem Herrschaftsantritt Konstans II. Folgendes:

131 Vgl. PL 129, 564 A8-16.

$132 \mathrm{PmbZ}$ Nr. 8107; J. HowARD-Johnston, Witnesses to a world crisis. Historians and histories of the Middle East in the seventh century. Oxford 2010, 268-312; W. TrEadgold, The middle Byzantine historians. New York 2013, 38-77. 
Iohannes aber, der Bischof von Rom, versammelte eine Bischofssynode und anathematisierte die Häresie der Monotheleten. ${ }^{133}$

Die Synode als solche bezeugt auch der Nachfolger Iohannes IV., Theodorus I. (642-649), in seiner Epistula synodica an den Konstantinopler Patriarchen Paulos II. (641-653), die nur im Auszug und in der lateinischen Rückübersetzung des Anastasius Bibliothecarius erhalten ist. ${ }^{134}$ In dem Ende 642/Anfang $643 \mathrm{zu}$ datierenden Schreiben wirft Theodorus Pyrrhos vor, er habe

unbesonnen den Skandal des Widerspruchs unter den Kirchen Gottes verbreitet und es geringgeschätzt, durch die beschwörende, inständige Bitte der Versammlung (obtestatione conventus) von unserem Vorgänger berichtigt zu werden. ${ }^{135}$

Demnach hat die römische Synode Pyrrhos beschworen, seine o.g. Maßnahmen zurückzunehmen und - so darf man schließen - die Ekthesis außer Kraft zu setzen. Von einer Anathematisierung berichtet Theodorus nichts. Zuvor hatte er an anderer Stelle des Briefes gesagt, dass

das, was von Pyrrhos gegen unseren apostolischen Glauben zur Vernichtung synodaler Entscheidungen vorgebracht wurde, durch die Lehre des apostolischen Stuhls, die von unserem Vorgänger dargelegt worden ist, und ebenso durch den Befehl unseres Sohnes, des allermildesten Fürsten, widerlegt worden ist. ${ }^{136}$

Der Papst hat hier offensichtlich die oben erwähnte ${ }^{137}$ konditionierte Bereitschaft der Reichsregierung unter Konstans II., ggf. aufgetretene Neuerungen auch wieder aufzuheben, in einen kaiserlichen Befehl gegen die Maßnahmen des Pyrrhos umgedeutet. Das von ihm erwähnte dogma sedis apostolicae, quod expositum est a praedesessore nostro, hat man ebenfalls auf die römische Synode bezogen. ${ }^{138} \mathrm{M}$. E.

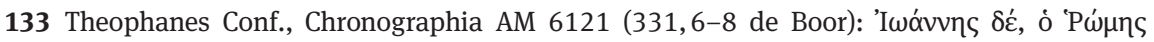

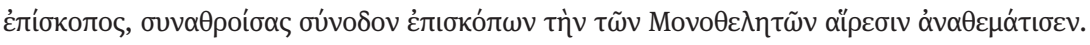

134 S. oben Fußnote 35. PL 129, 577-582 = PL 87, 75-80; WinkELmann, Streit (wie oben Fußnote 1) Nr. 79.

135 Theodorus I. pp., ep. synodica Paulo II. Patr. (PL 129, 580 C2-5 = PL 87, 79 A15-B1): Unde non modicum dissensionis scandalum Ecclesiis Dei disseminavit, et obtestatione conventus a decessore nosto corrigi parvipendit.

136 Theodorus I. pp., ep. synodica Paulo II. Patr. (PL 129, 579 B4-9 = PL 87, 78 A2-6): ea quae a Pyrrho adversus apostolicam fidem nostram ad subversionem synodalium decretorum prolata sunt, tam per dogma sedis apostolicae, quod expositum est a praedesessore nostro, quam per jussionem filii nostri mansuetissimi principis destructa sint.

137 S. oben Fußnote 85.

138 So CASPAR, Geschichte (wie oben Fußnote 23) 1933, 542 mit Anm. 1. 
jedoch beschreibt diese Formulierung eher die Apologia Honorii, die die römische Lehre (dogma), wie sie angeblich Honorius vertreten habe, authentisch darlegen will (expositum est).

Nicht eindeutig zu bestimmen ist der Zeitpunkt dieser Synode. Die ältere Forschung hat sie gegen Theophanes vor dem Tod des Herakleios am 11.2.641 datiert. Weil Iohannes IV. sein Amt erst am 24.12.640 antrat, müsste diese Synode dann sofort als seine erste Maßnahme von ihm einberufen worden sein. ${ }^{139}$ Diese Datierung beruht allerdings nur auf einer Aussage des Maximos Homologetes, die er in seinem Brief an den Patrikios Petros Illustrios, den Anastasius Bibliothecarius in seine Collectanea aufgenommen hatte, ${ }^{140}$ gemacht und während seines ersten Prozesses i.J. 655 wiederholt hatte: Kaiser Herakleios habe sich kurz vor seinem Tode angesichts des ausgebrochenen Streites von der Ekthesis distanziert und dies auch noch in einer - ansonsten nicht überlieferten - Keleusis ${ }^{141}$ Iohannes' IV. mitgeteilt. Diese Behauptung darf als widerlegt gelten durch die Entdeckung einer fragmentarisch erhaltenen tatsächlichen Keleusis des Kaisers an Iohannes IV., in der er eine von ihm verfasste Inschrift für eine Darstellung der Kreuzigung mitteilt, die eine eindeutig monotheletische Aussage enthält. ${ }^{142}$

139 So L. MAGI, La Sede Romana nella Corrispondenza degli Imperatori e Patriarchi Bizantini (VI-VII sec.), Louvain 1972, 207; van DieTEn, Patriarchen (wie oben Fußnote 1) 63.198; F. X. MURPHY/P. SHERWOOD, Konstantinopel II und III. Geschichte der ökumenischen Konzilien, 3. Mainz (1974) 1990, 202; J. F. HALDON, Byzantium in the seventh century. The transformation of a culture. Cambridge ${ }^{2} 1997$, 302. In neuerer Zeit DöLGER/MüLLER, Regesten (wie oben Fußnote 7) 97 (Reg. 221); BeIHAmmer, Nachrichten (wie oben Fußnote 70) 246.

140 Als dritten Text, s. oben Fußnote 33. Zu Petros Illustrios, dem Magister militum von Numidia, vgl. Winkelmann, Streit (wie oben Fußnote 1) Nr. 87, 88, 132 und S. 251. In diesem Schreiben von 645 hatte Maximos die Verteidigung des Honorius weiter auf die Spitze getrieben, insofern er unterstellte, dass die Berufung auf dessen Brief durch die Konstantinopler Patriarchen vor allen Dingen unter Inanspruchnahme der herausragenden Frömmigkeit des magnus Honorius erfolgt sei, der mit seinen Nachfolgern Severinus, Iohannes und Theodorus als divinus Honorius eine Einheit der Rechtgläubigkeit darstelle: „Gott indessen nimmt gewiss den Glauben dieser wirklich seligen Männer an und hat ihn im Wandel der Zeiten bewahrt“ (Sed Deus quidem horum profecto beatorum virorum fidem admisit, et pro ea vicissitudinem in saecula conservavit): Maximus Conf., ep. Petro Illustri (opusc. 12) [PG 91, 143 A14-B1, C3-6 = PL 129, A12-15, B15-C2]).

141 Maximus Conf., ep. Petro Illustri (opusc. 12): PL 91, 142C-143 A; Relatio motionis inter Maximum et principes 41, 370-378 (CC, SG 39 ALLEN/NEIL). DölgER/MüLLER, Regesten (wie oben Fußnote 7) Reg. 215; Winkelmann, Streit (wie oben Fußnote 1) Nr. 68.

142 S. Rizou-Couroupos, Un nouveau fragment de la keleusis d'Heraclius au pape Jean IV, in J. Dummer (Hrsg.), Texte und Textkritik. Eine Aufsatzsammlung. Texte und Untersuchungen, 133. Berlin 1987, 531-532; A. ALEXAKIS, Before the Lateran Council of 649: the last days of Herakleios the Emperor and Monotheletism. AHC 27/8 (1995/96) 93-101; W. BRANDES, „Juristische“ Krisenbewältigung im 7. Jahrhundert? Die Prozesse gegen Papst Martin I. und Maximos Homologetes, in L. Burgmann (Hrsg.), Fontes Minores, 10. Frankfurt/M. 1998, 141-212, hier 203 mit Anm. 99. 
Eine andere Datierungsmöglichkeit ergibt sich aus der Notiz, die das nach dem zweiten Rücktritt des Patriarchen Photios (858-867, 877-886) ${ }^{143}$ entstandene Synodicon vetus über diese Synode enthält:

Zusätzlich dazu versammelte der dreimalselige römische Papst Iohannes (denn er war der Nachfolger des Monotheleten Honorius) eine heilige und sakrale Synode. Dort anathematisierte er Sergios, Kyros und Pyrrhos und verkündete zwei Naturen und Wirkweisen unseres Herrn und Gottes Jesus Christus. Danach schickte er ein Dokument der Frömmigkeit (тúrov $\left.\varepsilon \dot{\sigma \varepsilon} \beta \varepsilon \varepsilon^{\prime} \alpha \varsigma\right)$ an die Söhne des Herakleios, David und Herakleios (Heraklonas). ${ }^{144}$

Dass es auf dieser Synode bereits zu einer namentlichen Anathematisierung zweier Konstantinopler und eines alexandrinischen Patriarchen gekommen sei, wird - wie schon erwähnt - seit langem als anachronistisch betrachtet. ${ }^{145}$ Dagegen spricht nicht nur die Bezeichnung des Pyrrhos als „unser Bruder“ in der Apologia Honorii. Auch Papst Theodor I. weiß bei aller scharfen Polemik gegen Pyrrhos in seiner eben erwähnten Synodica nichts von einer bereits erfolgten Anathematisierung. ${ }^{146}$ Gänzlich unglaubwürdig aber wird diese Information des Synodicon vetus dadurch, dass diese Konzilssynopse historisch falsch die vier afrikanischen Synoden des Jahres $646^{147}$ zeitlich vor die römische Synode platziert und bei jeder von ihnen stereotyp berichtet, sie hätten ebenfalls Sergios, Kyros und Pyrrhos anathematisiert. ${ }^{148}$ Dies steht jedoch im Widerspruch $\mathrm{zu}$ den auf der Lateransynode verlesenen Schreiben ${ }^{149}$ der afrikanischen Bischöfe, auf die sich die Angaben zu den afrikanischen Synoden beziehen. Bei Pyrrhos ist dies besonders abwegig, weil dieser wegen seiner gerade erfolgten Konversion zum Dyotheletismus im Brief der afrikanischen Bischöfe Columbus, Stephanus und Reparatus an Papst Theodor wegen seines „Libellus“ ausdrücklich als „unser Bruder“ bezeichnet wird. ${ }^{150}$ Darüber hinaus wird nun auch jedesmal mit fast gleichlautenden

143 PmbZ Nr. 6253, 26667.

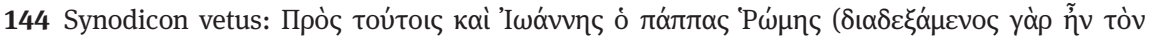

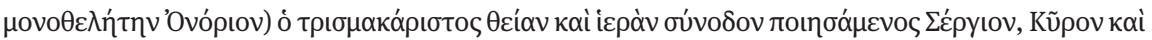

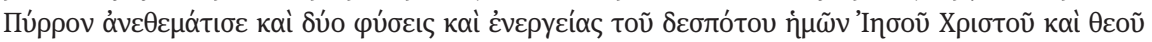

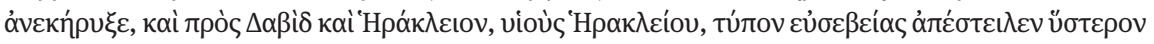
(Nr. 137 DUFFY/PARKER).

145 S. oben Fußnote 22.

146 Vgl. Theodorus I. pp., ep. synodica Paulo II. Patr.: PL 87, 79 C5-8.

147 Winkelmann, Streit (wie oben Fußnote 1) Nr. 98-101.

148 Synodicon vetus Nr. 133-136 (DufFy/PARKER).

149 Concilium Lateranense a. 649, ACO ser.II 2,1 p. 67, 21 - 71, 28; 75, 3 - 79, 23; 81, 9 - 95, 13; $99,6-103,43$.

150 Concilium Lateranense a.649, ACO ser. II 2,1 p. 69, 14: libellum Pyrri, nostri fratri et coepiscopi. Pyrrhos hatte nach seiner Konversion zum Dyotheletismus 647 in Rom Papst Theodorus 
Worten mitgeteilt, dass die Afrikaner „zwei Willen und Wirkweisen des Erlösers Christus“ verkündeten. ${ }^{151}$ Bei zwei Briefen ${ }^{152}$ der Afrikaner trifft das zu, aber diese sind vier bis fünf Jahre nach der römischen Synode geschrieben worden und standen unter dem direkten Einfluss des Maximos. Die Notiz des Syndicon vetus zur römischen Synode berührte demgegenüber auffälligerweise nicht die Willensthematik. Sie könnte deshalb möglicherweise größere Glaubwürdigkeit beanspruchen. ${ }^{153}$ M. Jankowiak hat in der ungewöhnlichen Erwähnung des Herakleiossohnes David, ${ }^{154}$ der seit Oktober 641 für einige Monate Mitregent des Herakleios (Heraklonas) war, ein Indiz für die Historizität dieser Angabe gesehen und die Synode von daher datiert. ${ }^{155}$ Üblicherweise wird hierin allerdings ein weiteres Beispiel für die historische Unzuverlässigkeit des Synodicon vetus gesehen. ${ }^{156}$

Etwa zeitgleich mit dem Synodicon vetus ist eine zweite, in ihrer Bedeutung diesem vergleichbare Konzilssynopse entstanden, die L.M. Hoffmann und W. Brandes kürzlich ediert haben. ${ }^{157}$ Die Herausgeber datieren sie in „die Jahre nach 865 und den Beginn der 80er Jahre des 9. Jh.s“ und lokalisieren sie in Konstan-

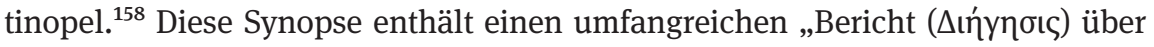

I. eine unterschriebene Erklärung (libellus) „in Gegenwart des gesamten Klerus und des Volkes“ überreicht, in der er ,alles, was von ihm und seinen Vorgängern gegen unseren unbefleckten Glauben geschrieben und unternommen wurde, verdammte.“(Liber Pontificalis 75, 3 [332, 10-12 DUCHESNE I]).

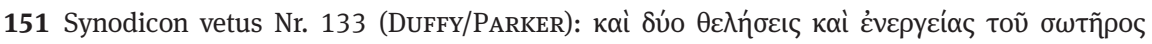

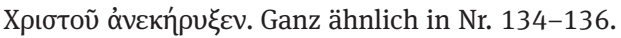

152 Synodalbrief der Bischöfe der Africa proconsularis: ACO ser.II 2, 1 p. 83, 27-13 (RIEDINGER); Synodica des Bischofs Victor von Karthago: ebd. 101,31-35.

153 Vgl. aber unten Anm. 166.

154 PmbZ Nr. 1241.

155 JanKowiak, Essai (wie oben Fußnote 4) 200-201.

156 Vgl. dazu Duffy/Parker, Synodicon vetus (wie oben Fußnote 19) 115 Anm. 164; Einleitung XV.

157 Hoffmann/ Brandes Konzilsynopse (wie oben Fußnote 87) 51-222.

158 Ebd. 28,29. Diese Synopse schloss ursprünglich mit dem VII. Ökumenischen Konzil. Im Kontext des III. Constantinopolitanums wird Photios, ep. I zitiert (174, 16-22), woraus sich der terminus post quem ergibt. Für die weitere Datierung gehen die Herausgeber davon aus, dass die Synopse eine Kanonessammlung benutzt habe, in der das Quinisextum fehlte, weil es ,überhaupt nicht erwähnt wird“ (24.291). Deshalb sei die Synopse in der zweiten Amtszeit des Photios entstanden, in der der Nomocanon XVI titulorum revidiert worden ist (28). Die Beobachtung zum Quinisextum trifft allerdings nicht zu, weil dessen Kanones in dieser Zeit im Osten längst als Kanones des VI. Konzils bezeichnet und zu ihm gerechnet wurden, und das Quinisextum deswegen gar nicht eigenständig erwähnt werden muss. Im Horos des VII. Konzil bezeichnet die Synopse selbst den ausführlich zitierten can. 82 des Quinisextums als Kanon des „sechsten 
die Häresie der Monotheleten, weshalb und in welcher Gegend sie entstand wie auch über verschiedene Lokalsynoden“. ${ }^{159}$ Dieser Bericht stellt „eine eigenständige Schrift dar, die der anonyme Autor (bzw. Kompilator) ... in sein Werk in toto inkorporiert hat.“160

Ganz ähnlich wie im Synodicon vetus wird auch hier die Willensthematik bei der Erwähnung des Kyros von Alexandrien ${ }^{161}$ und des Sophronios schon in die monenergetische Kontroverse vorverlegt. Letzterer habe auf einer - ansonsten unbekannten - Synode „zwei naturhafte Willen und zwei naturhafte Wirkweisen

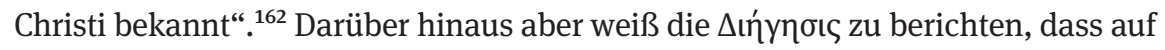
dieser Synode auch „Kyros, Sergios und Honorius und ihre Gesinnungsgenossen exkommuniziert worden seien“. ${ }^{163}$ Ebenso wie das Synodicon vetus rückt sie sodann die vier afrikanischen Synoden zeitlich vor Iohannes IV. und lässt sie genauso namentliche Anathematismen über „Kyros, Sergios und Pyrrhos“ aussprechen und „zwei naturhafte Willen und Wirkweisen“ in Christus bekennen. ${ }^{164}$ Sodann wird über die römische Synode berichtet:

Das Gleiche setzte durch weitere göttliche Synoden auch Iohannes von Rom durch, deren Akten er auch nach Konstantinopel an die Kaiser, nämlich Konstantin und Heraklonas, die Söhne des Herakleios, senden ließ. ${ }^{165}$

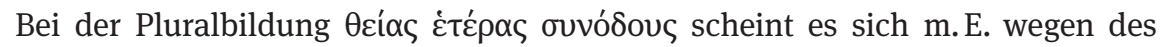
singularischen Anschlusses $\tilde{\eta} \varsigma$ um einen Schreiberfehler zu handeln. Mit der

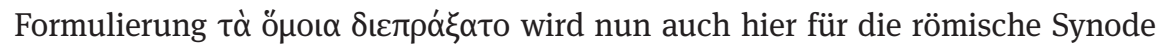
eine namentliche Anathematisierung und - noch über das Synodicon vetus hin-

heiligen und ökumenischen Konzils“ (198, 138-151). Damit wäre auch ein späteres Entstehungsdatum denkbar.

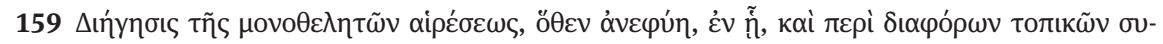

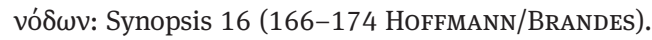

160 HofFMann/Brandes, Konzilsynopse (wie oben Fußnote 87) 283.

161 Vgl. Synodicon vetus (wie oben Fußnote 19), Nr. 130 (DufFy/PArKer) mit Synopsis 16 (166, 16-17 HOFFMANN/BRANDES).

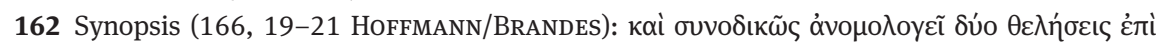

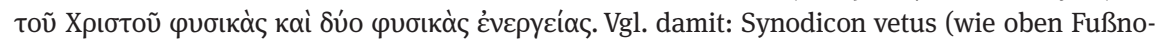
te 19) Nr. 131 (Duffy/PARKer).

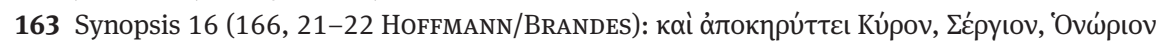

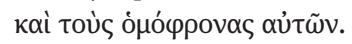

164 Synopsis 16 (168, 29-39 HofFmann/Brandes).

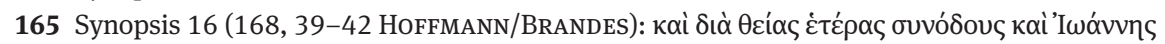

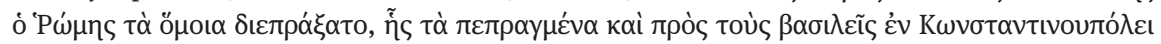

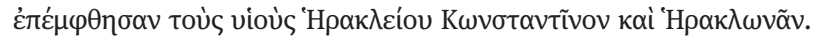


ausgehend $^{166}$ - auch ein dyotheletisches Bekenntnis postuliert. Allerdings ergibt sich dieses Postulat klar aus der zeitlichen Vorordnung der afrikanischen Synoden und den ihnen zugeordneten anachronistischen Aussagen. Es kann dann gar nicht mehr erwartet werden, dass bei der römischen Synode Iohannes' IV. etwas anderes oder gar weniger bestimmt worden sein könnte. Aber damit nicht genug, lässt der

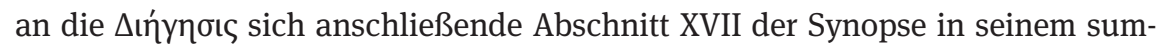
marischen Bericht über das VI. Ökumenische Konzil bei der Auflistung der dort Anathematisierten Honorius von Rom einfach weg! ${ }^{167}$ In dem danach wörtlich wiedergegebene Horos der Synode ist Honorius allerdings enthalten. ${ }^{168}$ Diese Merkwürdigkeit ist m. E. nur so zu erklären, dass der erste summarische Teil von

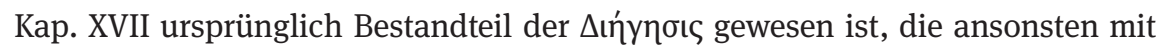
der römischen Synode unter Papst Agatho von 680 und ohne das VI. Konzil als Abschluss geendet hätte, was wenig wahrscheinlich ist. Der Kompilator der Synopsis aber musste an dieser Stelle einen neuen Abschnitt beginnen und

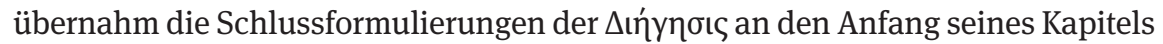
zum VI. Konzil. Dass damit innerhalb dieses Kapitels ein Widerspruch zum folgenden Horos der Synode entstand, scheint ihm nicht aufgefallen zu sein. Aber „konzeptionelle Überlegungen sollte man ihm ... nicht unterstellen. Vermutlich folgte er einfach den Quellen (der Quelle?), die ihm zur Verfügung standen. “169

Damit ergibt sich für diese $\Delta$ เńynбıৎ folgendes Bild. Eine Verurteilung des Honorius wird bereits früh in einer (Jerusalemer?) Synode unter Sophronios verortet, wobei ein terminologischer Unterschied $\mathrm{zu}$ den behaupteten Anathematismen der afrikanischen Synoden und dann natürlich auch zu den Anathematismen des VI. Konzils auffällt. War es hier stets das Anathema, so ist es bei der

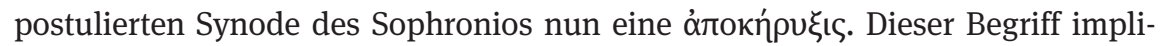
ziert ebenfalls Verurteilung und Ausschluss, jedoch im Sinne einer Aufhebung der Gemeinschaft durch Exkommunikation, nicht aber die Anathematisierung eines Häretikers. ${ }^{170}$ Indem die Erwähnung der Anathematisierung des Honorius auf dem VI. Konzil vermieden wird, entsteht so eine deutlich mildere Sicht über dessen

166 M.E. ist allerdings zu vermuten, dass auch im Synodicon vetus an dieser Stelle anstelle $\varphi$ vecıৎ ursprünglich $\theta \varepsilon \lambda \hat{n} \sigma \varepsilon ı$ s gestanden hat. Die handschriftliche Überlieferung ist freilich eindeutig, vgl. ebd. 144 (DufFY/PARKER) zur Stelle. $\theta \varepsilon \lambda \hat{\sigma} \sigma \varepsilon ı s$ begegnet nur in späteren Handschriften des 16. Jh.s; die älteste Handschrift des Synodicon vetus stammt aus dem 12. Jh. (ebd., Einleitung, XVI). 167 Synopsis 17 (172, 7 - 174, 11 HofFMANn/Brandes).

168 Synopsis 17 (178,58-62 HoFFMANN/BRANDES).

169 Hoffmann/Brandes, Konzilsynopse (wie oben Fußnote 87) Kommentar zu Abschnitt XII, 249.

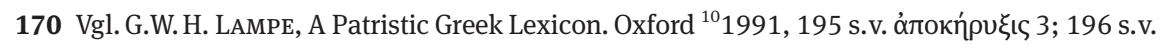

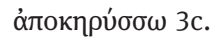


Verfehlung. Dazu kommt Folgendes. Dieser „Bericht über die Häresie der Monotheleten“ betont in sehr auffälliger Weise die Bedeutung des Maximos Homologetes: Er sei es gewesen, der „durch die heiligen Synoden (sc. die afrikanischen) die Häretiker anathematisierte“. ${ }^{171}$ Eine von diesen, die Synode von Byzakion, „versammelte sich durch den Eifer und die Mithilfe des Bekenners Maximos. “172 Die Lateransynode wird zwar von Papst Martin I. einberufen, aber „von dem großen Bekenner Maximos mitgeleitet“. ${ }^{173}$ Auffällig ist schließlich die extensive Prädikation von Maximos und Papst Martin I. als Bekenner, Märtyrer und Heilige. ${ }^{174}$ Damit sind hier nicht nur Insiderinformationen über den wesentlichen strategischen und theologischen Beitrag des Maximos in seinem Kampf gegen die

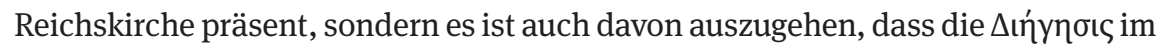
Kontext aktiver Märtyrer- und Heiligenverehrung von Papst Martin I. und Maximos entstanden ist. Ähnliche Beobachtungen lassen sich bei der griechischen Vita Papst Martins (BHG 2259) und der Anastasios Sinaites zugeschriebenen Synopsis

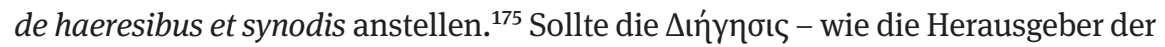
Synopse meinen ${ }^{176}$ - ,vermutlich ... nicht lange nach dem Constantinopolitanum III (680/81)“ entstanden sein, so ist hier m. E. an den engeren Kreis der Maximianer in Jerusalem/Palästina zu denken, denn eine offizielle Heiligenverehrung dieser beiden Personen ist $\mathrm{zu}$ diesem Zeitpunkt hier $\mathrm{zu}$ lokalisieren. ${ }^{177}$ Wir haben in diesem „Bericht“ also eine maximianische Perspektive auf den monenergetischmonotheletischen Streit vorliegen, die aus einer Sicht auf Honorius, wie sie der Apologia Honorii entspricht, den Schluss zog, seine Verurteilung durch das VI. Ökumenische Konzil zu verschweigen und durch eine temporäre Exkommunikation durch den Patriarchen Sophronios zu ersetzen. Dabei handelt es sich um die älteste Quelle, die der römischen Synode von 641 eine namentliche Anathematisierung sowie ein dyotheletisches und dyenergetisches Bekenntnis zuordnet.

171 Synopsis 16 (168, 29 Hoffmann/Brandes).

172 Synopsis 16 (168, 31 (HoFfMANN/Brandes).

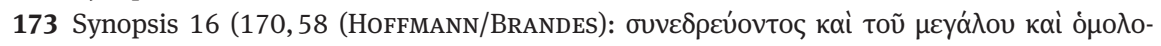

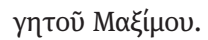

$174 \mathrm{Zu}$ Maximos vgl. Synopsis (168,26; 170,58; 172,1; 172,72 Hoffmann/Brandes); zu Martin I. ebd., 170, 66; 172, 72-73.

175 Vgl. H. Онме, Der lange Widerstand gegen eine offizielle Heiligenverehrung des Maximos Homologetes (†662) im Byzantinischen Reich. BZ 109 (2016) 109-150, 129-131; DERs., Die griechische Vita Papst Martins (BHG 2259), Maximus Confessor und das Concilium Quinisextum (691/2). Byzantion 85 (2016) 317-336.

176 Hoffmann/Brandes, Konzilsynopse (wie oben Fußnote 87) Kommentar 283.

177 Vgl. OHмE, Widerstand (wie oben Fußnote 175) 122-131. 
In der Überlieferung der römischen Synode unter Iohannes IV. lässt sich somit ebenfalls eine Fortschreibung beobachten, die ihr Endstadium in der 2. Hälfte des 9. Jh.s erreicht zu haben scheint. Aus einer römischen Synodalentscheidung des Jahres 641, die sich gegen die Maßnahmen des Pyrrhos zur Durchsetzung einer gesamtkirchlichen Rezeption der Ekthesis wandte und ihn dringend aufforderte, diese zu revozieren - so Papst Theodorus I. -, wurde eine Synode mit Anathematismen - sei es pauschal gegen den Monotheletismus (so Theophanes), oder namentlich gegen Sergios, Kyros und Pyrrhos (so das Synodicon vetus und die $\Delta ı$ ńyøıৎ) -, die schließlich auch schon das dyenergetische und dyotheletische Bekenntnis der Lateransynode und des VI. Konzils vorweggenommen hat. Auch in dieser Überlieferung sind wir auf die aktive Beteiligung von Anhängern des Maximos Homologetes am Überlieferungsprozess gestoßen und mit dem Synodicon vetus, das von einem „undisguised partisan of Ignatius“ in antiphotianischem Geist zusammengestellt wurde, ${ }^{178}$ in den Kontext einer Kontroverse gelangt, in der die Apologia Honorii auch zum ersten Mal literarisch belegt ist. Wir werden deshalb jetzt diesem Konflikt einige Aufmerksamkeit schenken müssen.

\section{Das Interesse an der Orthodoxie des Honorius während der Kontroverse um den Konstantinopler Patriarchen Photios}

Anastasius Bibliothecarius, Herausgeber und Übersetzer der in den Collectanea versammelten Texte, ist eine der Schlüsselfiguren jenes Konfliktes, dessen Höhepunkte die Absetzung und Exkommunikation des Konstantinopler Patriarchen Photios (858-867, 877-886) ${ }^{179}$ durch eine römische Synode unter Papst Nicolaus I. $(858-867)^{180}$ i.J. 863 und die Absetzung und Exkommunikation dieses Papstes durch eine von Photios als Ökumenisches Konzil durchgeführte Konstantinopolitanische Synode i. J. 867 darstellen. In dieser Kontroverse ging es wesentlich auch um die gesteigerten Primatsansprüche des römischen Papsttums, die unter Nicolaus I. und Hadrian II. (867-872) ${ }^{181}$ ihren Höhepunkt im Frühmittelalter erreichten. ${ }^{182}$ Äußerer Anlass der Konfrontation war bekanntlich die Erhebung des

178 DufFy/Parker, Synodicon vetus (wie oben Fußnote 19) Introduction XIII.

179 PmbZ Nr. 6253.26667.

180 PmbZ Nr. 5248.

181 PmbZ Nr. 22537.

182 Vgl. z. B. J. FRIED, Nicolaus I. TRE 24 (1994) 535-540; H. GROTZ, Erbe wider Willen. Hadrian II. (867-872) und seine Zeit. Wien u.a. 1970. 
Laien Photios zum Patriarchen im Jahre 858 anstelle des abgesetzten Mönches Ignatios (847-858; 867-877), ${ }^{183}$ für den Papst Nicolaus ab 862 Partei ergriff. Auf der Konstantinopler Synode von 869/70 („VIII. Ökumenisches Konzil“) gelang es der römischen Kirche zwar, die Absetzung des Photios und Wiedereinsetzung des Ignatios durchzusetzen, gleichzeitig musste sie aber in der mit dem Konflikt verbundenen Frage der jurisdiktionellen Zuständigkeit für die bulgarische Missionskirche deren definitiven Verlust hinnehmen.

Nach eigenem Bekunden hat Anastasius als päpstlicher Diktatgeber in den sieben Jahren vor 869 fast alles verfasst (pene omnia), was unter den Päpsten Nicolaus und Hadrian im Fall Ignatios/Photios vom apostolischen Stuhl herausgegeben worden war. ${ }^{184}$ An der Abschlusssitzung der Synode am 28. 2. 870 hatte er teilgenommen, als er sich als Mitglied einer Gesandtschaft des fränkischen Kaisers Ludwig II. ${ }^{185}$ für einige Zeit in Konstantinopel aufhielt. ${ }^{186}$ Nach seiner Rückkehr wandte er sich einer umfangreichen Übersetzungstätigkeit ${ }^{187}$ griechischer Texte zu, zu denen auch die Texte der Collectanea gehören. Von diesen 15 Texten zum monotheletischen Streit dienen 6 Texte dem Versuch der Rehabilitation ${ }^{188}$ des Papstes Honorius mit der Apologia Honorii an der Spitze. Anastasius macht dies in seinem Brief an Iohannes Diaconus ${ }^{189}$ nicht nur dadurch deutlich, dass ca. $80 \%$ des Briefes diesem Thema gewidmet sind, sondern er sagt es auch ausdrücklich: Durch die Übersetzungen ,begehren wir darzulegen, dass in dem Felsen des apostolischen Stuhles - so viel den Glauben anlangt - auch nicht durch Honorius jemals die Spur der Schlange, d.h. einer giftigen Lehre, gefunden worden ist. “190

Anastasius bietet dazu eine Fülle von Argumenten auf, die schließlich sogar darauf abzielen, die Anathematisierung des Honorius durch das VI. Ökumenische Konzil in Frage zu stellen. So sei der Angriff gegen Honorius von „falschen An-

183 PmbZ Nr. 2666.

184 Anastasius Bibl., Praefatio ad acta VIII. Synodi: MGH Epp. VII 410, $23-29$ (PERELs/LAEHR). 185 PmbZ Nr. 24755.

186 J.D. MANSI, Sacrorum conciliorum nova et amplissima collectio. Florenz $1759 \mathrm{ff} .$, XVI, 158B5-11; Anastasius Bibl., Praefatio ad acta VIII. Synodi: MGH Epp. VII 410,15-18 (PERELS/ LAEHR).

187 Vgl. NEIL, Popes (wie oben Fußnote 27) 35-91.

188 Dies sind die oben aufgelisteten (s. oben S. 94-95) Texte 1-3 und 5-7.

189 S. oben Fußnote 28.

190 Anastasius Bibl., ep. Iohanni diac.: MGH Epp. VII 425,9-11 (Perels/LaeHR); NeIL, Popes (wie oben Fußnote 27) 156,17-21: ostendere gestientes, quod in apostolicae sedis petra, quantum ad fidem pertinet, nec etiam per Honorium inventum sit unquam serpentis, id est virulentiae sectae, vestigium. 
klägern“ geführt worden. ${ }^{191}$ Der Brief Iohannes’ IV. mache Honorius „entschuldbar, obwohl das VI. heilige Konzil das Anathema gegen ihn ausgesprochen hat, als ob er Häretiker sei (quasi heretico) und ihn mit dem Speer der Verwerfung durchbohrt hat, unterliegt er doch allein dem Urteil Gottes“. ${ }^{192}$ Wer könne schließlich sagen, dass er den Brief selbst diktiert habe ${ }^{193}$ Dazu wird eine Fülle von Schriftstellen aufgeboten, um das Verbot vorschneller Verurteilung zu belegen. ${ }^{194}$ Ohne die Autorität des VI. Konzils in Frage stellen zu wollen, müsse jedoch in Rechnung gestellt werden, dass der Hl. Stuhl seit den Päpsten Gelasius und Gregor I. keineswegs alle Entscheidungen ökumenischer Synoden rezipiert habe, was am Beispiel Chalcedons und des I. Constantinopolitanum verdeutlicht wird. ${ }^{195}$ Deshalb gelte:

Es gebührt uns unserer Meinung nach über jene (sc. die VI. Synode) so zu denken, wie wir wissen, dass unsere hl. Väter über die große Synode von Chalcedon gedacht haben. ${ }^{196}$

Anastasius Bibliothecarius spielt also auf die Ablehnung von can. 28 des IV. Ökumenischen Konzils und can. 3 des II. Ökumenischen Konzils durch die römische Kirche $\mathrm{an}^{197}$ und intendiert offensichtlich ein analoges Verhalten gegenüber der Anathematisierung des Honorius bei unveränderter Anerkennung der dogmatischen Beschlüsse des III. Constantinopolitanums. Diese äußerst provokante Argumentation macht die Frage dringlich, worin denn die Ursache für dieses aktuelle und extensive Interesse an der Rehabilitation des Honorius bestand.

191 Anastasius Bibl., ep. Iohanni diac.: MGH Epp. VII 423, 34 (Perels/LAeHR); NeIL, Popes (wie oben Fußnote 27) 150,17: a calumniatoribus.

192 Anastasius Bibl., ep. Iohanni diac.: MGH Epp. VII 423, 35-37 (Perels/LAEHR); NeIL, Popes (wie oben Fußnote 27) 150, 18 - 152, 2: Quae videlicet apologia satis hunc ut reor excusabilem reddit; licet huic sancta sexta synodus quasi heretico anathema dixerit et in Dei solius iam positum reprobationis telo confoderit.

193 Anastasius Bibl., ep. Iohanni diac.: MGH Epp.VII 424, 2-7 (Perels/LaeHR); NeIL, Popes (wie oben Fußnote 27), 152, 4-12.

194 Anastasius Bibl., ep. Iohanni diac.: MGH Epp. VII 424,9-24 (Perels/LaeHR); NeIL, Popes (wie oben Fußnote 27) 152,13 - 154, 5.

195 Anastasius Bibl., ep. Iohanni diac.: MGH Epp. VII 424, 24 - 425, 7 (Perels/LAEHR); NeIL, Popes (wie oben Fußnote 27) 154, 6 - 156, 15.

196 Anastasius Bibl., ep. Iohanni diac.: MGH Epp. VII 424, $28-29$ (Perels/LAeHR); NeIL, Popes (wie oben Fußnote 27) 154,10-12: licere nobis opinamur de illa sentire, quae sanctos patres nostros de Chalcedonensi magna synodo sensisse non ignoramus.

197 Can. 3 von 381 erhebt Konstantinopel anstelle Alexandriens in der Rangfolge auf den 2. Platz

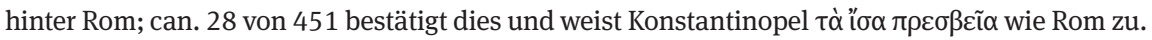
Die römische Kirche verstand dies als eine Infragestellung ihres Primates. Vgl. OHME, Sources (wie oben Fußnote 63) 52-53, 63-66 (Literatur ebd. 58). 
Es ist davon auszugehen, dass Anastasius Bibliothecarius zu den gegenwärtigen „falschen Anklägern“ des Honorius vor allem Photios rechnete. ${ }^{198}$ Dieser hatte sich schon in seiner Epistula Inthronistica vom Jahre 860 an Papst Nicolaus nicht gescheut, bei seiner Bestätigung des VI. Ökumenischen Konzils Honorius an die erste Stelle der dort verurteilten Häretiker zu rücken und ihn ohne Papsttitulatur als „Fabeldichter“ und „Wahnsinnigen“ zu bezeichnen. ${ }^{199}$

Papst Nicolaus I. hatte sodann auf einer nochmaligen Untersuchung der Vorgänge um die Absetzung des Ignatios unter römischer Beteiligung bestanden. ${ }^{200}$ Kaiser Michael III. (20.1.842 [15.3.856] - 23.9.867) ${ }^{201}$ und Photios waren ihm sehr weit entgegengekommen, als sie eine synodale Revision dieser Entscheidung unter Beteiligung zweier römischer Legaten ${ }^{202}$ akzeptierten, die i. J. 861 in der Apostelkirche in Konstantinopel stattfand. ${ }^{203}$ Dort bestätigten die päpstlichen Legaten die Rechtmäßigkeit der Absetzung des Ignatios. Ab 862 weigerte sich Nicolaus jedoch zur völligen Überraschung der Konstantinopolitaner, das Urteil seiner Legaten zu bestätigen, ${ }^{204}$ erklärte die Einsetzung des Photios für illegitim, bezeichnete diesen als „Ehebrecher und hochgradigen Frevler“205 und erklärte Ignatios zum einzig legitimen Patriarchen von Konstantinopel. Dies teilte er am 18.3.862 in drei Briefen ${ }^{206}$ an den Kaiser, an Photios und in einer Enzyklika allen

198 So bereits Perels/LAeHr, in MGH Epp. VII 423 Anm. 7.

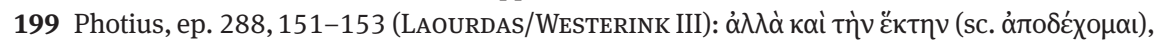

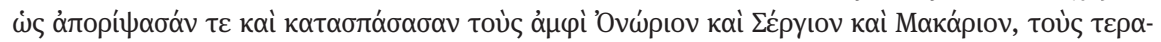

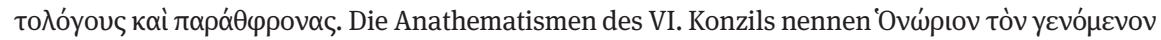

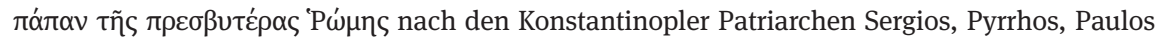
und Petros und vor Kyros, Makarios usw. (ACO ser. II 2, 2 p. 772, 6-10). Diese korrekte Reihenfolge ist Photios bekannt, denn in seinem Brief an den Bulgarenfürst (Boris) Michael hält er sie ein: Photios, ep. 1, 329-334 (LAOURDAs/WESTERINK I 12).

200 In seinem Brief an Kaiser Michael vom 25.9.860: ep. 82 (MGH Epp. VI 433-439).

201 PmbZ Nr. 4991.

202 Dies waren die Bischöfe Rhadoaldus von Porto (PmbZ Nr. 6404) und Zacharias von Anagni (PmbZ Nr. 8636).

203 Zur Synode von 861 vgl. M.V. AnAStos, The papal legates at the Council of 861 and their compliance with the wishes of the Emperor Michael III, in ders., Aspects of the mind of Byzantium. Political theory, theology, and ecclesiastical relations with the See of Rome, ed. by S.Vryonis, jr. / N. Goodhue. Aldershot u. a. 2001, Nr. VI (S. 185-200); D. STIERNON, Konstantinopel IV. Geschichte der ökumenischen Konzilien, 5. Mainz 1975, 39-57; F. DvoRnık, The Photian Schism. History and legend. Cambridge 1948 (Ndr. 1970), 70-90; GROTZ, Erbe wider Willen (wie oben Fußnote 181) 65-73.

204 In seinen Schreiben vom 18.3.862 an den Kaiser (ep. 85) und Photios (ep. 86): MGH Epp.VI 442-446, 447-451 (PERELS).

205 Nicolaus I., ep. 84 (MGH Epp. VI 442, 17 PERELS): pervasore coniugis ... scelestissimo videlicet Photio.

206 Nicolaus I., ep. 84-86 (MGH Epp. VI 440-450 PERELS). 
Gläubigen und allen östlichen Patriarchen, Metropoliten und Bischöfen mit. Die Provokation wird für Photios und den Kaiser nicht nur in der Entscheidung als solcher und ihrer Publikation bestanden haben, sondern mehr noch in ihrer Begründung. Denn der aus dem primatialen Selbstverständnis der Petrusnachfolge und -stellvertretung abgeleitete universalistische Anspruch, dass das, „was von den Leitern dieses Stuhles mit ganzer Vollmacht festgesetzt wird ... , umso fester und unerschütterlich einzuhalten ist“, ${ }^{207}$ wurde von ihm auf die Aussage der Unfehlbarkeit der römischen Kirche zugespitzt. In seinem Brief an den Kaiser beruft sich Nicolaus darauf, dass die „heilige, katholische und apostolische römische Kirche, das Haupt aller Kirchen, immer und in allen ihren Handlungen dem unverfälschten Ansehen der heiligen Väter gefolgt ist. “208 In dem Schreiben an Photios behauptet der Papst, dass die Gesamtheit der Gläubigen von der „heiligen römischen Kirche, die das Haupt aller Kirchen ist, Belehrung verlangt, die Unversehrtheit des Glaubens (integritatem fidei) fordert und die Beendigung der Vergehen (sc. des Photios) erbittet.“209

Überdies hatte die Konstantinopler Synode von 861 mit ihrer definitiven Absetzung des Ignatios zu einer Fluchtbewegung der Anhänger des Ignatios nach Rom geführt, insbesondere von Mönchen, darunter auch dem ehemaligen Exarchos des Ignatios, Theognostos. ${ }^{210}$ Dieser überreichte in Rom einen Libellus, ${ }^{211}$ der im Namen ${ }^{212}$ von Ignatios, 10 Metropoliten, 15 Bischöfen und einer „unendlichen Menge von Äbten, Presbytern und anderen Mönchen“ an „unseren Herrn, den hochheiligen und allerseligsten Vorsitzenden und Patriarchen aller Bischofssitze und Nachfolger des Ersten (sc. Petrus) und ökumenischen Papst Nicolaus“ ge-

207 Nicolaus I., ep. 86 Photio (MGH Epp. VI 448,6-7 PERELS): et ideo consequens est, ut, quod ab huius sedis rectoribus plena auctoritate sancitur ... firmius atque inconcusse teneatur.

208 Nicolaus I., ep. 85 Michaeli Imp. (MGH Epp. VI 443,5-7 PERELS): hanc sanctam catholicam et apostolicam, caput omnium ecclesiarum, Romanam scilicet ecclesiam, quae semper sanctorum patrum sincerissimas auctoritates in omnibus suis actibus sequitur.

209 Nicolaus I., ep. 86 Photio (MGH Epp.VI 447,32-34 PERELS): et quia universitas credentium ab hac sancta Romana ecclesia, quae caput omnium est ecclesiarum, doctrinam exquirit, integritatem fidei deposcit, criminum solutionem ... exorant.

210 PmbZ Nr. 8018. Nicolaus erwähnt in ep. 88 ihn „und einige andere Mönche“, die nach Rom geflohen seien, „wie unzählige andere Christen“, „die aus Alexandrien, Jerusalem, aus Konstantinopel und seiner Umgebung, vom Berg Olymp und von allen Ländern der Erde sich einfanden in Rom und alle dasselbe berichteten über das Ignatios widerfahrene Unrecht“: Nicolaus I., ep. 88 (MGH VI 477,21f.,24; 478,28-30[PERELS]: quod ipsi per innumeros homines Romam ab Alexandria, ab Hierosolymis, a Constantinopoli et confinibus eius, ab Olimpo monte atque an ceteris mundi partibus advenantes agnovimus).

211 MANSI (wie oben Fußnote 186), XVI, 295-302.

$212 \mathrm{Ob}$ Theognostos hier auf eigene Initiative oder im Auftrag des Ignatios gehandelt hat, lässt sich nicht mehr entscheiden. Vgl. dazu PmbZ Nr. 8018, Anm. 4. 
richtet ist, ${ }^{213}$ und mit Verweis auf can. 4 der Synode von Serdika (342) bei ihm appelliert. ${ }^{214}$ Unter Verweis auf seine Vorgänger Fabianus, Julius, Innocentius, Leo „und alle, die für die Wahrheit gegen die Ungerechtigkeit gekämpft haben“, wird Nicolaus aufgefordert, diesen nachzueifern und diejenigen, die Ignatios Ungerechtigkeit widerfahren lassen, einer gerechten Strafe zuzuführen. ${ }^{215}$ Damit waren durch dieses Appellationsschreiben die primatialen Ansprüche des Papsttums auf gesamtkirchliche Zuständigkeit bei Bischofsprozessen als höchste Appellationsinstanz von den Gegnern des Photios anerkannt worden. Nicolaus hat daraufhin vollständig die Partei der Ignatianer ergriffen und nach den Briefen vom 18.3.862 im Juli/August 863 eine römische Synode durchgeführt, auf der Photios seines Amtes enthoben und in den Laienstand zurückversetzt wurde, während Ignatios als rechtmäßiger Patriarch anerkannt wurde. ${ }^{216}$ Theognostos blieb ca. 7 Jahre in Rom $^{217}$ und mit ihm eine große Anzahl von ignatianisch gesinnten Mönchen aus dem Osten. Diese bildeten jetzt die Mehrheit unter den griechischen Mönchen in Rom $^{218}$ und bestimmten dort dermaßen das kirchenpolitische Klima, dass noch der Nachfolger des Nicolaus, Hadrian II., bei seinem Regierungsantritt am 12.2.868 für diese Gruppe von Mönchen aus Jerusalem, Antiochien, Alexandrien und Konstantinopel ein Festessen veranstaltete, bei dem er selbst sie zu ihrer Überraschung bediente und in einer Ansprache ihnen versicherte, die Politik seines Vorgängers gegenüber Konstantinopel fortzusetzen. ${ }^{219}$

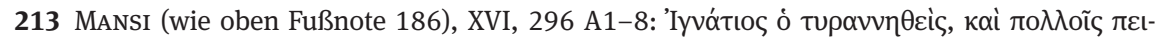

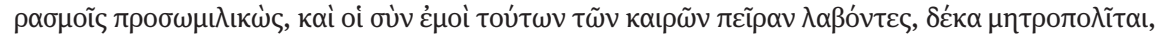

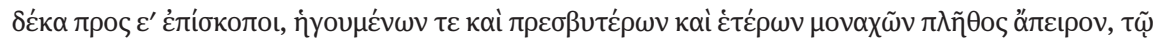

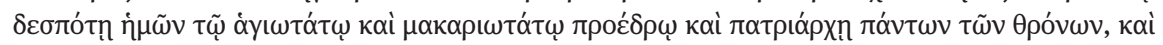

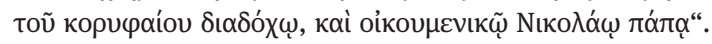

214 MANSI (wie oben Fußnote 186), XVI, 297 E5-10. Zu den Appellationskanones von Serdika vgl. OHмE, Sources (wie oben Fußnote 63) 66-74.

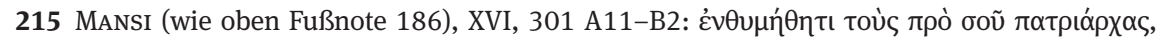

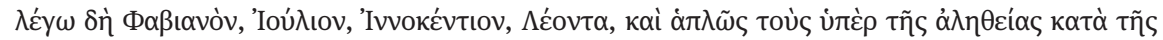

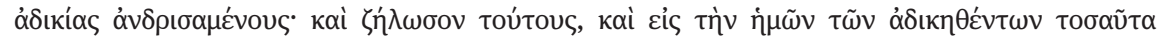

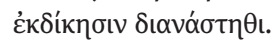

216 Nicolaus I., ep. 87 (MGH Epp.VI 451-452 PeRELS), ep. 98 (ebd. 556,12-557,10; 562,8-23). Zur Synode vgl. W. Hartmann, Die Synoden der Karolingerzeit im Frankenreich und in Italien. Paderborn 1989, 288-290.

217 Vgl. PmbZ Nr. 8018, Anm. 3.

218 J.-M. SANSTERRE, Les moines grecs et orientaux à Rome aux époques byzantine et carolingienne (milieu du VIe s.-fin du IXe s.). Bruxelles 1983, I 141.

219 Liber Pontificalis CVIII, 16-19 (176,18-177,17 Duchesne II); GROTZ, Erbe wider Willen (wie Anm.182) 141-144 spricht von einer „Regierungserklärung“ Hadrians vor den Mönchen; SANSTERRE, Les moines grecs (wie oben Fußnote 218) 39.141-143, meint, Hadrian habe den Einfluss der Mönche anerkannt als „un véritable ,group de pression““(SANSTERRE, ebd., 143). 
Kaiser Michael III. aber hatte Nicolaus im August 865 ein äußerst provokantes Schreiben ${ }^{220}$ gesandt, mit dem er auf die päpstlichen Briefe vom 18.3.862 reagierte. Der kaiserliche Brief, als dessen Autor Nicolaus wohl zu Recht Photios annahm, ${ }^{221}$ ist nicht erhalten, seine wesentlichen Inhalte können aber aus der Antwort Papst Nicolaus' an den Kaiser erschlossen werden, die - wie alle zuvor genannten Briefe des Papstes - von Anastasius Bibliothecarius verfasst worden ist. Dieser äußerst umfangreiche Brief ${ }^{222}$ macht $\mathrm{m}$. E. deutlich, wieso die Honoriusfrage jetzt in den Focus des päpstlichen Interesses und damit auch des Anastasius geriet. Denn das kaiserliche Schreiben war ,voll von Beleidigungen und Angriffen gegen die römische Kirche“6223 und Drohungen, Rom den Untergang zu bereiten, wenn der Papst nicht sein Urteil revidierte. ${ }^{224}$ In gleicher Weise strotzt die päpstliche Antwort vor beißender Schärfe und wirft alle diplomatischen Rücksichtnahmen über den Haufen. Diese kaum je zuvor so gehörte antikaiserliche Aggressivität erklärt sich aus der polemischen Infragestellung des beanspruchten gesamtkirchlichen Jurisdiktionsprimates der römischen Kirche durch Konstantinopel. Nicolaus will in seinem Brief das widerlegen, was „,zur Beschimpfung der römischen Kirche, was zur Minderung ihrer Vorrechte und was zur Aufhebung (ad derogationem) der Vollmacht der Bischöfe des apostolischen Stuhles“ geschrieben wurde. ${ }^{225}$ Der an erster Stelle von ihm behandelte kaiserliche Vorwurf bringt nun sofort das VI. Ökumenische Konzil ins Spiel. Der Kaiser habe gesagt, seit dem VI. Konzil habe kein einziger römischer Bischof so viel Entgegenkommen vom Kaiser erlangt, wie Nicolaus. ${ }^{226}$ Das nimmt natürlich auf das kaiserliche Zugeständnis Bezug, auf der Synode von 861 nochmals unter Beteiligung von römischen Legaten die Rechtmäßigkeit der Absetzung des Ignatios zu verhandeln. ${ }^{227}$ Insofern es aber um die

220 DöLger/Müller, Regesten (wie oben Fußnote 7) Reg. 464; StIERnon, Konstantinopel IV (wie oben Fußnote 203) 55-57.

221 Nicolaus I., ep. 88 (MGH Epp. VI 473,28; 474,16 PERELS).

222 Nicolaus I., ep. 88 (MGH Epp. VI 454-487 PERELS). Er stellt eine der wichtigsten Manifestationen des päpstlichen Selbstverständnisses im Mittelalter dar und wurde später von allen bedeutenden Kanonisten bis zu Gratian zitierend herangezogen. Vgl. E. Perels, Die Briefe Nikolaus I. Die kanonistische Überlieferung. NA 39 (1914) 45-153.292-294.

223 A. MÜLLER in: DöLGER/MÜLLER, Regesten (wie oben Fußnote 7) 240 (Reg. 464). S. dort auch die Zusammenfassung der Angriffe.

224 Nicolaus I., ep. 88 (MGH Epp. VI 479,1-4 PERELS).

225 Nicolaus I., ep. 88 (MGH Epp. VI 456,40-457,1 PERELS): Verumtamem quae ad ecclesiae Romanae iniuriam, quae ad ipsius privilegiorum imminutionem, quae ad sedis apostolicae derogationem scripsistis, quanta possumus constantia retundemus.

226 Nicolaus I., ep. 88 (MGH Epp. VI 457,2-4 PERELS): Dixistis enim, quod nullus antecessorum nostrorum a sexta synodo meruerit a vobis, quod nos meruisse dinoscimur.

227 Vgl. Anm. 203. 
Absetzung eines Konstantinopler Patriarchen ging, ist der eigentliche Bezugspunkt die römische Beteiligung an der Absetzung von vier Konstantinopler Patriarchen auf dem VI. Konzil i.J. 681. Damit wird aber automatisch auch die dortige Verurteilung des Honorius mit aufgerufen. Obwohl sich dies nun in Ermangelung des kaiserlichen Briefes nicht belegen lässt, ist m. E. davon auszugehen, dass in diesem Brief auch mit Hinweisen auf Honorius zur Zurückweisung der römischen Unfehlbarkeitsansprüche argumentiert worden ist. Anders lässt sich m. E. die unmittelbar folgende außerordentlich gereizte Replik des Papstes kaum verstehen, der sich zu dem Gegenvorwurf versteigt, dass „seit dem VI. Konzil die meisten Kaiser Häretiker waren und nur wenige katholisch. “228 Gegen die kaiserliche Infragestellung der römischen Ansprüche argumentiert Nicolaus schließlich, dass

niemand zu keinem Zeitpunkt sich durch einen ganz und gar menschlichen Beschluss erheben dürfe gegen das Vorrecht und das Bekenntnis Jenes, den der Befehl Christi allen ... als Ersten offenbart hat. ${ }^{229}$

Insofern hier nicht nur jurisdiktionelle Privilegien, sondern auch das Bekenntnis römischer Päpste angesprochen ist, transzendiert dieser Satz die aktuelle Problemlage und lässt vermuten, dass der Briefschreiber in Hinsicht auf das VI. Konzil bereits von der Unschuld des Honorius überzeugt ist. Schließlich argumentiert der Brief sogar ausdrücklich mit dem monotheletischen Streit, insofern auch noch Maximos aufgerufen wird, der „ehrwürdige Mönch und in jener Zeit bei euch fast der einzige Katholik“, ${ }^{230}$ der in seinem Prozess das Nötige zu den Grenzen der kaiserlichen Gewalt gesagt habe. Das bezieht sich auf eine Stelle in der sog. Relatio motionis, die Anastasius erst im Zusammenhang seiner Collectanea ca. 10 Jahre später übersetzen wird, die ihm aber offensichtlich schon jetzt bestens bekannt ist. $^{231}$

Honorius, Maximos und der monotheletische Streit stehen also in den Kontroversen um Photios und Ignatios in den 60er Jahren des 9. Jh.s auf beiden Seiten argumentativ im Hintergrund. In diesem Kontext ist nun auch erstmals die Apo-

228 Nicolaus I., ep. 88 (MGH Epp. VI 457,18-19 PERELS): Denique an sexta synodo imperatores aut heretici aut, licet perpauci, catholici fuerunt.

229 Nicolaus I., ep. 88 (MGH Epp. VI 485,23-24 PERELS): numquam quovis penitus humano consilio elevare se quemquam posse contra illius privilegium vel confessionem, quem Christi vox praetulit universis.

230 Nicolaus I., ep. 88 (MGH Epp.VI 486,25-26 PERELS): Maximus, venerabilis monachus et illo in tempore apud vos pene solus catholicus.

231 Collectanea Nr. 9; Relatio motionis inter Maximum et principes (25,182-27,206 CChr.SG 39 Allen/NeIL); Vgl. dazu G. Dagron, Emperor and Priest. The Imperial Office in Byzantium. Cambridge 2003, 168-173; OHME, Maximos (wie oben Fußnote 39) 321-325. 
logia Honorii literarisch belegt. Woher aber hat Anastasius Bibliothecarius diesen Text eigentlich erhalten? Und warum ist er als kohärenter Text nicht schon früher belegt?

\section{Die Entstehung des bei Anastasius Bibliothecarius überlieferten Textes der Apologia Honorii}

Wie eingangs bereits festzustellen war, hat der Bibliothecarius Romanae Ecclesiae den Text der Apologia Honorii nicht im römischen Archiv vorgefunden, er ist ihm vielmehr nach seinen Worten in griechischer Übersetzung ,in die Hände gefallen. “232 Dies aber kann nicht in Rom der Fall gewesen sein, denn der Brief Papst Iohannes' IV. an die Kaiser war offensichtlich bereits vor dem VI. Ökumenischen Konzil in Rom nicht mehr greifbar. Das ergibt sich aus folgenden Beobachtungen.

Kaiser Konstantin IV. (668-685) ${ }^{233}$ hatte in seiner Sacra ${ }^{234}$ an Papst Donus (676-678) ${ }^{235}$ vom 12.8.678 und der dort ausgesprochenen Einladung, zur Klärung der theologischen Streitfrage eine Delegation nach Konstantinopel zu entsenden, bereits darauf hingewiesen, dass die Patriarchen Theodoros von Konstantinopel (677-679.686-687) $)^{236}$ und Makarios von Antiochien (669-681) ${ }^{237}$ ihn bedrängt hätten, außer Honorius dessen Nachfolger auf dem römischen Stuhl insgesamt bis zur Klärung der Streitfrage aus den Diptychen zu streichen. ${ }^{238}$ Neben Klerikern und Bischöfen - so teilte der Kaiser weiterhin mit - solle die römische Delegation auch Vertreter der „vier byzantinischen Klöster in Rom“ enthalten; man möge auch die entsprechenden Bücher mitbringen. ${ }^{239}$ Damit war bereits im Vorfeld der Synode eigentlich klar, dass die Monotheleten sich auch 40 Jahre nach Pyrrhos weiterhin auf Honorius berufen würden, und man sollte erwarten, dass in Rom entsprechende Vorbereitungen getroffen wurden. Davon ist allerdings vor und während der Synode nicht das Geringste zu bemerken. ${ }^{240}$ Selbst Papst Agatho (678-681) ${ }^{241}$

232 S. oben Fußnote 41.

233 PmbZ Nr. 3702.

234 DöLGER/MüLLER, Regesten (wie oben Fußnote 7), Reg. 242.

235 PmbZ Nr. 1392.

236 PmbZ Nr. 7317.

237 PmbZ Nr. 4670.

238 Constantinus IV. Imp., Sacra Dono Papae: $A C O$ ser. II 2,2 p. 8,11-18 (RIEdinger).

239 Constantinus IV. Imp., Sacra Dono Papae: ACO ser. II 2,2 p. 6,11.30-31 (RIEDINGER).

240 Vgl. zum Folgenden: KreUZER, Honoriusfrage (wie oben Fußnote 2) 82-93.97-100. 
hat seinen Brief ${ }^{242}$ an den Kaiser vom 27.3.680 anscheinend ohne jedes Problembewusstsein angesichts der Honoriusfrage formuliert. Er argumentiert dort nicht nur unbeirrt mit der völligen Irrtumsfreiheit ${ }^{243}$ der römischen Kirche, sondern vertritt auch noch den Standpunkt, dass die römischen Bischöfe es niemals versäumt hätten, die Bischöfe der Kirche von Konstantinopel zu ermahnen, wenn diese eine häretische Neuerung in die Kirche einzuführen versuchten, damit sie nicht den Anfang der Spaltung in die Kirche brächten, ,indem sie einen Willen und eine Wirkweise der beiden Naturen in einem Herrn Jesus Christus geltend machen“. ${ }^{244}$ Auf dem VI. Konzil hatte sich dann Makarios von Antiochien schon in der 1. Sitzung in seiner Antwort an die römischen Legaten auf Honorius bezogen, ${ }^{245}$ ebenso in der 8. Sitzung, ${ }^{246}$ um dann auf eine Sendung mit Testimonia an den Kaiser zu verweisen, zur der u.a. auch der 1. Honoriusbrief gehörte. Diese Testimonia wurden ab der 12. Sitzung diskutiert und verworfen. ${ }^{247}$ „Die päpstlichen Legaten, die bisher am regsten und führend in den Debatten des Konzils gewesen waren, verhielten sich während dieser ganzen Episode schweigend. “248 Bis zur abschließenden Anathematisierung des Honorius sind keinerlei Versuche der Legaten, Honorius zu verteidigen, nachweisbar. Dies betrifft auch die vier Vertreter $^{249}$ der Klöster. Diese hatten das grundlegende römische Florilegium für die Synode zusammengestellt mit 61 Testimonia aus 39 verschiedenen Werken und durften auch die erste Lesung daraus vornehmen. ${ }^{250}$ Der zu dieser Gruppe gehörende Abt des sizilianischen Klosters $\tau \tilde{\omega} v$ Boî́ $\omega v$, Theophanes, ${ }^{251}$ war „ohne

241 PmbZ Nr. 129.

242 Agatho I., ep. Constantino IV. Imp.: ACO ser. II 2,2 p. 52,13-123,4 (RIEDINGER); WinKELMANN, Streit (wie oben Fußnote 1) Nr. 157.

243 Agatho I., ep. Constantino IV. Imp.: ACO ser. II 2,2 p. 63,14-15; 113,1-4 (RIEDINGER). Genauso argumentiert der Synodalbrief der Lateransynode vom 27.3.680: ACO ser. II 2,2 p. 125,11127,2 .

244 Agatho I., ep. Constantino IV. Imp.: ACO ser. II 2,2 p. 67,8-13 (RIEDINGER): numquam neglexerunt eos hortari atque obsecrando commonere ... ne ex hoc exordium discidii in unitate ecclesiae facerent, unam voluntatem unamque operationem duarum naturarum asserentes in uno domino Iesu Christo.

245 Concilium Constantinopolitanum a. 680/81, actio I: ACO ser. II 2,2 p. 22,18-19 (RIEDINGER). 246 Ebd., actio VIII: ACO ser. II 2,2 p. 216,23 (RIEDINGER).

247 Concilium Constantinopolitanum a.680/81: ACO ser. II 2,2 p.524,5-18; 548,1-558,8; 564,1-17; 578,12-580,8 (RIEDINGER)

248 CASPAR, Geschichte (wie oben Fußnote 23) 602.

249 Vgl. z.B. Concilium Constantinopolitanum a.680/81: ACO ser. II 2,2 p. 38,34-40,1 (RIEDINGER).

250 Vgl. SANSTERRE, Les moines grecs (wie oben Fußnote 218) 120-121.

$251 \mathrm{PmbZ} \mathrm{Nr}$. 8082. Er wurde auf dem Konzil nach der Absetzung des Makarios von Antiochien zu dessen Nachfolger erhoben. 
Zweifel der beste Theologe auf dem Konzil“ und trieb Makarios und dessen Schüler in Befragungen mehrfach in die Enge. ${ }^{252}$ Zur Verteidigung des Honorius aber hatte auch er nichts zu sagen. Das alles kann nur bedeuten, dass den römischen Legaten nicht nur die Apologia Honorii unbekannt war, sondern auch die ganze Honoriusproblematik einschließlich der Honoriusbriefe. Das muss auch für Papst Agatho gelten, der ansonsten seine Legaten ohne Zweifel auf diese Thematik vorbereitet hätte. Diese Beobachtungen haben schon G. Kreuzer zu folgendem Schluss geführt: „Wenn die Honoriusbriefe im päpstlichen Archiv vorhanden gewesen wären, hätte sie Agatho sicherlich seinen Legaten mitgegeben. ${ }^{\text {“253 }} \mathrm{Zu}$ ergänzen ist nunmehr, dass er natürlich vor allem auch die Apologia Honorii mitgegeben hätte, wenn sie noch im Archiv gewesen wäre. Dieses merkwürdige Fehlen hat Kreuzer m.E. zutreffend dadurch erklärt, dass „die römische Geistlichkeit also vermutlich ihr eigenes Beweismaterial selbst beseitigt hatte“. ${ }^{254} \mathrm{Er}$ vermutet, dass dies zwischen der Entstehung der Apologie und dem Amtsantritt Papst Martins am 5.7.649 geschehen sei. ${ }^{255}$ Man könnte präzisieren, dass dies nach 642/43 während des Papates von Theodorus I. erfolgt sein muss, der die Apologie in seinem o.g. Brief an Kaiser Konstans II. ja noch erwähnt. ${ }^{256}$

Ein so radikales Vorgehen gegen die bereits im Zusammenhang der Vorbereitung der Lateransynode von $649^{257}$ wohl als kompromittierend betrachteten Honoriusbriefe und die Apologie korrespondiert mit dem völligen Ausfall von diesbezüglichen Nachrichten im Liber Pontificalis. Denn dessen Nachrichtensperre betrifft nicht nur das bereits erwähnte Kapitel ${ }^{258}$ über Iohannes IV., in dem von dessen Synode und der Apologie keine Rede ist, sondern auch das Kapitel

252 MURPHy/SHERwood, Konstantinopel II und III (wie oben Fußnote 139) 242.

253 KREUZER, Honoriusfrage (wie oben Fußnote 2) 98.

254 KreUzer, Honoriusfrage (wie oben Fußnote 2) 99. „Ich vermute, daß auf Veranlassung des Abtes Johannes und des Diakons Sericus die Kopien der beiden Honoriusbriefe unterdrückt worden sind. Beide hätten, wäre die Rechtgläubigkeit der beiden Schreiben auch in Rom umstritten gewesen, um ihre Stellungen bangen müssen.“ (a.a.O.). Sericus war römischer Archidiakon unter Honorius und Iohannes IV. Der 2. Honoriusbrief an Patriarch Sergios nennt ihn als Verfasser (ACO ser.II 2,2 p. 620,23 RIEDINGER). Wahrscheinlich ist er auch der Überbringer der Apologia Honorii nach Konstantinopel und der Antwort Konstans' II. nach Rom. Vgl. Dölger/Müller, Regesten (wie oben Fußnote 7) Reg. 221, Kommentar.

255 Ebd.

256 S. oben S. 115 mit Anm. 136-138.

257 Auf der Lateransynode kommt Iohannes IV. außer als Empfänger eines Briefes von Pyrrhos nicht vor (ACO ser.II 1, p. 338,17 [RIEDINGER]). Er wird weder als Verfasser der Apologie noch als Veranstalter einer Synode genannt. Honorius wird überhaupt nicht erwähnt, obwohl Maximos noch 645 den Glauben des „magnus Honorius“ gepriesen hatte (vgl. Anm. 140).

258 S. oben S. 93 mit Anm. 25. 
über Honorius, der im Papstbuch nur als Bauherr und Ordinator auftaucht, nicht aber als Briefpartner des Sergios. ${ }^{259}$ Damit nicht genug, berichtet der Liber Pontificalis im Kapitel über Papst Agatho ziemlich detailliert über die Vorgänge auf dem VI. Konzil nur bis zur 9. Sitzung mit der Absetzung des Makarios von Antiochien und schließt den Bericht mit der Verurteilung von Kyros, Sergios, Pyrrhos, Paulos und Petros, ohne Honorius mit einem Wort zu erwähnen. ${ }^{260}$

Der Text der Honoriusbriefe und der Apologia Honorii existierte damit schon vor dem VI. Konzil nicht mehr in Rom - weder im päpstlichen Archiv noch in den Bibliotheken der griechischen Klöster - , sondern nur noch im griechischen Osten. Deswegen ist m. E. davon auszugehen, dass Anastasius Bibliothecarius die Apologia Honorii entweder durch die in Rom weilenden ignatianischen Mönche ,in die Hände gefallen“ war, die - wie dargestellt - ein direktes Interesse an der uneingeschränkten Autorität des römischen Stuhles hatten und vielleicht den Brieftext

259 Liber Pontificalis 72 (323-324 Duchesne I).

260 Liber Pontificalis 81,6-14 (351,10-354,15 DuCHESNE I). Andere Erklärungen gehen allesamt auf L. Duchesne (Liber Pont. I, 356, Anm. 13) zurück, der meinte, dass die Akten der Synode dem Schreiber der Vita Agathonis noch nicht vorlagen oder noch nicht übersetzt waren. Die vom Liber Pontificalis gebotenen Informationen über die Synode seien vorher brieflich nach Rom gelangt. Ähnlich: CASPAR (Geschichte [wie oben Fußnote 23] 609). SHERwood (MurPHy/SherwooD, Konstantinopel II und III [wie oben Fußnote 139] 252 mit Anm. 43) konzediert, dass es „ohne Zweifel ... bewußt unterlassen (wurde), das zu erwähnen“, und will dies damit erklären, dass die „authentische Bestätigung“ durch Papst Leo II. noch nicht vorlag. Diese ist mit dem Schreiben Leos vom September 682 erfolgt (WinkELmann, Streit [wie oben Fußnote 1] Nr. 168). In der Vita Leonis des Liber Pontificalis wird Honorius dann tatsächlich erwähnt (359,9 DUCHESNE I), allerdings ohne Titel nur unter Nennung des Namens. Die Akten der Synode wurden nach Abschluss des Konzils den römischen Legaten im September 681 überreicht (ACO ser. II, 2,2 p. 830, 1-5) und von diesen im Sommer 682 Rom nach gebracht, wo man sofort mit der lateinischen Übersetzung begann. (R. RIEDINGER, Die lateinischen Handschriften der Akten des VI. Konzils (680/81) und die Unizialkorrekturen im Cod.Vat. Regin. Lat. 1040, in: DERS., Kleine Schriften zu den Konzilsakten des 7. Jahrhunderts. Instrumenta Patristica, 34. Steenbrugge 1998, 119-133, 123). Diese Erklärungen für das Fehlen des Namens des Honorius übersehen Folgendes. Der Liber Pont. 81,6 (351,12 Duchesne I) spricht von 150 Teilnehmern der Synode, eine Zahl, die erst mit der 17. Sitzung fünf Tage vor Abschluss der Synode erreicht wurde (Vgl. R. RIEDINGER, Die Präsenz- und Subskriptionslisten des VI. ökumenischen Konzils [680/81] und der Papyrus Vind.G.3. ABAW philos.-histor. Klasse NF, 85. München 1979, 21). Ebenso berichtet er von einer „die octava Paschae" in der Hagia Sophia in lateinischer Sprache gefeierten Messe, die zwischen der 14. Und 15. Sitzung stattgefunden haben muss (354,13; 358 Anm. 33 Duchesne I). Mit M. JANKowiak, dem diese Beobachtungen zu verdanken sind, ist daraus zu schließen, dass der Bericht des Liber Pont. „sans doute après leur (sc. der Legaten) retour à Rome en juillet 682“ entstanden ist (DERS., Essay [wie oben Fußnote 4] 437). Die bewusste Auslassung des Honorius in der Vita Agathonis im Liber Pont. ist m. E. auch aus der Überlegung heraus erfolgt, ansonsten das Kapitel über Honorius umschreiben zu müssen. 
bei sich führten, oder er hat ihn mit den anderen Texten der Collectanea während seines Aufenthaltes in Konstantinopel i.J. 870 gesammelt und nach Rom gebracht. Letzteres scheint mir wahrscheinlicher zu sein. $\mathrm{Zu}$ den vielen Texten, die Anastasius aus Konstantinopel mitbrachte, gehören z.B. auch die Ps.DionysiusScholien des Maximos Homologetes und des Johannes von Skythopolis. Und von diesen berichtet er mit einer ähnlichen Formulierung wie bei der Apologia Honorii, sie seien ihm ,in die Hände gekommen“. ${ }^{261}$ Bekanntlich hat Anastasius auch einen eigenen Codex mit einer in seinem Auftrag gefertigten Kopie der Akten der antiphotianischen Synode von 869/70 nach Rom mitgebracht. ${ }^{262}$ Seine lateinische Übersetzung ist der einzige erhaltene Protokolltext dieser Synode. Ebenso hat er in Konstantinopel den dortigen griechischen Aktentext des VII. Ökumenischen Konzils (787) studiert und dabei festgestellt, dass in dem Brief Papst Hadrians I. an die Kaiser Konstantin VI. und Irene Veränderungen vorgenommen wurden. Seine lateinische Übersetzung der Akten der Bildersynode basiert auf einem griechischen Aktentext, der sich durch Zusätze und Lücken von jenem durch die päpstlichen Legaten 787 nach Rom gebrachten Exemplar deutlich unterscheidet und dessen Entstehung „im Zusammenhang der Auseinandersetzungen zwischen Nikolaus I. und Photios zu sehen ist“. Er stellt das „Ausgangsexemplar der Gesamtüberlieferung dar.“ Es ist auch in diesem Fall davon auszugehen, dass Anastasius diesen Text in einem ,zeitgenössischen griechischen Codex ... wohl aus Konstantinopel mitgebracht hat. “263 Nimmt man die anderen vom ihm mitgeführten Texte hinzu, so muss der päpstliche Bibliothekar seinen Konstantinopelaufenthalt für ausgiebige Handschriftenstudien genutzt haben. Ohne Zweifel ist er dabei auf Hilfe - nicht zuletzt beim Kopieren - angewiesen gewesen. Seine Kontakte und Informationen gewann er ,in ultra-Ignatian circles, which he frequented at the time.“264 Anastasius berichtet selbst ${ }^{265}$ von ausführlichen Gesprächen mit dem Metropoliten von Smyrna, Metrophanes, ${ }^{266}$ der zu den Hauptgegnern des Photios gehörte. Auch der inzwischen i.J. 868 nach Konstantinopel zurückgekehrte und zum Abt des Pegeklosters und Skeuophylax der Hagia Sophia aufgestiegene Theognostos wird hilfreiche Dienste geleistet haben. Bei diesen

261 Anastasius Bibl., ep. 13 Karolo (Calvo) Imp., MGH Epp.VII 432,14 (Perels/LAEHR): ad manus venere.

262 Anastasius Bibl., Praefatio ad acta VIII. synodi, MGH Epp. VII 410,29-34. (PERELS/LAEHR). 263 Alle Zitate stammen vom Herausgeber der Akten des VII. Konzils, E. LAMBERZ, in: DeRs. (Hrsg.), Concilium Universale Nicaenum Secundum. Concilii Actiones I-III. ACO ser. II 3,1, Berlin 2008, Einleitung LIII. Zur lateinischen Übersetzung des Anastasius vgl. ebd., XXXII-L.

264 Dvornik, The Photian Schism (wie oben Fußnote 203) 33.

265 Anastasius Bibl., ep. Gauderico episc. Veliternensi, MGH Epp. VII 437, 6-11 (PERELs/LAEHR). 266 PmbZ Nr. 25088. 
Handschriftenstudien wird Anastasius Bibliothecarius auf eine kanonistische Sammelhandschrift gestoßen sein, die wie jene späteren oben beschriebenen arabischen Übersetzungen ${ }^{267}$ zum VI. Ökumenischen Konzil neben einer kurzen historischen Einleitung und dem Horos sowie den Kanones auch die Apologia Honorii und die Briefe Konstans' II. und Papst Theodorus' enthielt. Dieser Codex sollte sich an einem Ort befunden haben, der Überlieferungsträgern zuzuordnen ist, die an der Orthodoxie des Honorius ein spezifisches Interesse hatten, ist dieser Textbestand - wie gesagt - doch ansonsten in griechischen kanonistischen Sammelhandschriften nicht belegt.

Ein durchgängiges Interesse an der Orthodoxie des Papstes Honorius ist von Anfang an bei Maximos Homologetes und seinen Anhängern festzustellen gewesen. Seit dem Besuch des engsten Mitarbeiters des Maximos, Anastasios Monachos, i.J. 641 in Rom ist dies evident. ${ }^{268}$ In Opusculum 20 von 641 unternimmt Maximos selbst eine Apologia Honorii, ${ }^{269}$ in seinem Brief an Petros Illustrios von 645 stellt er Honorius in eine Reihe mit den Päpsten Severinus, Iohannes und Theodorus. ${ }^{270}$ In der Disputatio cum Pyrrho wird von den maximianischen Autoren nach 655 zur Verteidigung des Honorius der ursprüngliche theologische Inhalt der Apologia Honorii Iohannes IV. so präzise referiert und auf eine bestimmte Stelle des 1. Honoriusbriefes Bezug genommen, dass man annehmen muss, dass die Texte beider Briefe dort vorlagen. In der nach dem VI. Konzil m.E. in maximianischen

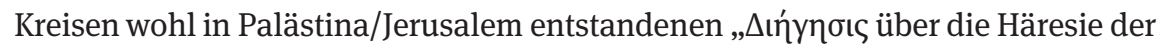
Monotheleten“ wird die Anathematsierung des Honorius auf dem VI. Konzil unterschlagen und dafür eine frühere temporäre Exkommunikation konstruiert. Gleichzeitig wird hier (außerhalb des überlieferten Textes der Apologia Honorii!) erstmals Iohannes IV. ein dyotheletisches Bekenntnis zugeordnet. ${ }^{271}$

Dieses Interesse des Maximos und seiner Anhänger ist vor und nach der Lateransynode von 649 über die Person des Honorius hinaus ein Interesse an der uneingeschränkten Autorität des Papsttums als Institution. Denn dieses Mönchskollektiv aus Palästina geflohener Mönche hat in Kooperation mit dem aus Jerusalem stammenden griechischen Papst Theodorus I. (642-649) das Papsttum und die von einem Papst geleitete Synode gleichsam für seine kirchenpolitisches Ziele instrumentalisiert und in zelotischem Geist die Konfrontation mit Kirche und

267 S. o. Kap. 1.

268 S. oben Fußnote 123.

269 S. oben Fußnote 127.

270 S. oben Fußnote 140.

271 S. oben S. 121. 
Staat gesucht. ${ }^{272}$ Maximos Homologetes hat deshalb bekanntlich wie kein anderer östlicher Theologe vor und nach ihm Autorität, Primat und Privilegien der römischen Kirche betont. ${ }^{273}$ Durch die Lateransynode von 649, für die die Autorität eines ökumenischen Konzils in Anspruch genommen wurde, ${ }^{274}$ die aber die Karikatur einer kirchlichen Synode war, ${ }^{275}$ sollte mit päpstlicher Autorität den maximianischen Theologumena universale Geltung verschafft werden. ${ }^{276}$ Dies alles aber ließ sich kaum mit einem Papst vereinbaren, der in den Anfängen derselben Kontroverse die Partei der Gegenseite ergriffen hatte. Deswegen ist der anfänglichen Interpretation des Honoriusbriefes durch Iohannes IV. schließlich ein eindeutig dyotheletisches Bekenntnis zugewachsen. Diese Fortschreibung ist m. E. in maximianischen Kreisen nach 681 erfolgt. Denn trotz der auf dem VI. Konzil erfolgten Rezeption der dyotheletischen Theologumena des Maximos war man bei den Maximianern anscheinend nicht bereit, die Gleichordnung des Honorius mit Sergios, Pyrrhos, Paulos und Petros ohne weiteres mitzutragen. Hinzu kam, dass das VI. Konzil jede Würdigung des Maximos und der Lateransynode vermieden hat, während die Maximianer einen Heiligen- und Märtyrerkult um Maximos und Papst Martin installierten. ${ }^{277}$ Dieser Heiligenkult wurde gegen Ende des 8. Jh.s in den ikonodulen monastischen Kreisen Konstantinopels rezipiert, ${ }^{278}$ die sich zunehmend radikalisierten, so dass sich schließlich in den Tagen des Patriarchen Photios in Konstantinopel „two powerful hostile clans“ gegenüberstanden,

272 Dazu vgl. Chr. Boudignon, Le pouvoir de l'anathème ou Maxime le Confesseur et les moines palestiniens du VIIe siècle, in: A. Camplani/G.Filoramo (Hrsg.), Foundations of Power and Conflict of Authority in Late Antique Monasticism. Orientalia Lovaniensia Analecta, 157. Leuven u.a. 2007, 245-274; Воотн, Crisis (wie oben Fußnote 3) 278-300; H. ОнмE, Oikonomia im monenergetisch-monotheletischen Streit. Zeitschrift für Antikes Christentum 12 (2008) 308-343); DERS., Die Bedeutung der Geschichtstheologie im monenergetisch-monotheletischen Streit. Zeitschrift für Theologie und Kirche 112 (2015) (27-61) 41-51, DERS., Martyrium (wie oben Fußnote 39).

273 Vgl. J.-C. Larchet, Saint Maxime le Confesseur. Paris, 2003, 198-210; Ders., Maxime le Confesseur, médiateur entre l'Orient et l'Occident. Paris, 1998, 125-201.

274 Maximos hat die Lateransynode so bezeichnet: Opuscula theol. et polem. 11 (PG 91, 137D). 275 Vgl dazu: R. RIEDINGER, Die Lateransynode von 649 und Maximus der Bekenner, in: Kleine Schriften (wie oben Fußnote 261)167-179; DERS., Die Lateranakten von 649, ein Werk der Byzantiner um Maximos Homologtetes, ebd., 221-238; PRICE, Lateran Synod of 649 (wie oben Fußnote 25),5-108 (General Introduction); H. OHмE, Was war die Lateransynode von 649? Was sollte sie sein?. AHC 47 (2015) (im Druck).

276 Dies ergibt sich u. a. aus der Forderung, dass die zuvor in Rom kopierten und an alle großen Kirchen verschickten Akten überall synodal rezipiert werden sollten. Vgl. dazu die Enzyklika Papst Martins I.: ACO ser. II 2,1 p. 412,2-4.11-12 (RIEDINGER).

277 OHME, Widerstand (wie oben Fußnote 175), 113-131.

278 Ebd. 131-141. 
„which were competing for supreme control over church and state.“ Auf der einen Seite waren dies „the partisans of ,oeconomia', the liberal policy of compromise“, auf der anderen „the intransigent ultra-conservatives, who held that church prescriptions should be carried ut in all circumstances and with the utmost rigour.“279 Die letzteren waren die Anhänger des Ignatios, die besonders stark im Mönchtum vertreten waren und hier von allem unter den Mönchen des Konstantinopler Studios-Klosters. ${ }^{280}$ Wir haben gesehen, wie in dieser Kontroverse um Photios nun erneut Honorius und das Interesse an einer uneingeschränkten Autorität des Papsttums für die Ignatianer und die Protagonisten auf der päpstlichen Seite aktuell wurde.

Für die Entstehung einer sehr begrenzten Tradition kanonistischer Handschriften mit den genannten Ergänzungen bieten sich somit m.E. zwei Erklärungen an. Im Zusammenhang der zelotischen Rezeption der Maximos-Verehrung und maximianischer Traditionen könnte die inzwischen fortgeschriebene Apologia Honorii zusammen mit den anderen Texten in den Skriptorien ignatianischer Klöster Konstantinopels, die während des Ikonoklasmus neu entstanden waren, ${ }^{281}$ in die kanonistische Tradition zum VI. Konzil eingewandert sein. Als Ort hierfür wäre vor allem das Studios-Kloster zu denken. ${ }^{282}$ Ebenso aber könnte eine solche Ergänzung bereits im maximianischen Kontext palästinischer Klöster erfolgt ein, um dann in Konstantinopel übernommen worden zu sein.

279 Alle Zitate: DvoRnık, Schism (wie oben Fußnote 203) 5-6. Zu den konkreten Ursachen der Spaltung der Kirche von Konstantinopel vgl. DvoRnik, ebd. 1-38; B. Zielke, Methodios I., in R.-J. Lilie (Hrsg.), Die Patriarchen der ikonoklastischen Zeit. Berliner Byzantinistische Studien, 5. Frankfurt a.M. 1999, 183-260, hier 230-259.

280 Vgl. Dvornik, Schism (wie oben Fußnote 203) 9: ,chiefly the reformed monks of the monastery of Studion“; GROTZ, Erbe wider Willen (wie oben Fußnote 182) 62: „Die entschiedensten Parteigänger des Ignatios waren die Studiten.“

281 Die Entstehung von byzantinischen Klosterskriptorien wird insbesondere mit dem Ikonoklasmus Ende 8./Anfang 9. Jh. verbunden, weil den Ikonodulen der Zugang zu bestehenden Bibliotheken verwehrt wurde. „We have here a new departure in the function of the Byzantine monastery. The close contacts which the Orthodox monks maintained with their brethren in the Arab-dominated East as well in the West may have facilitated the process; Palestine, it would seem, was still fairly well supplied with Greek manuscripts": C. MANGo, The availability of books in the Byzantine empire, A.D. 750-850, in: Byzantine books and bookmen. Washington 1975, 2945, hier 44.

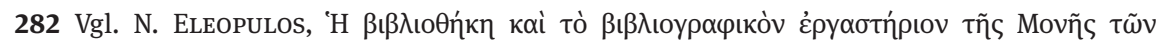

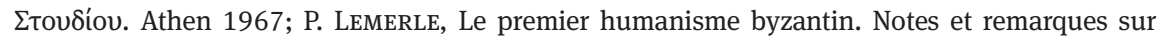
enseignement et culture à Byzance des origines au X $\mathrm{X}^{\mathrm{e}}$ siècle. Paris 1971, 121-128; TH. PRATSCH, Theodoros Studites (759-826) - zwischen Dogma und Pragma. Berliner Byzantinische Arbeiten, 4. Frankfurt/M. 1998, 123-125. 
Fazit: Mit der vorliegenden Rekonstruktion der Entstehung des überlieferten Textes der Apologia Honorii Papst Iohannes’ IV. wird die äußerst ungewöhnliche Tatsache nachvollziehbar, dass von diesem Text weder das lateinische Original existiert, noch auch die griechische Übersetzung, die der Rückübersetzung des Anastasius Bibliothecarius zugrunde gelegen hat. Es wird erklärbar, warum dieser Text erstmals i.J. 874/75 literarisch belegt ist und seine handschriftliche Verankerung nur in einer sehr schmalen Tradition byzantinischer kanonistischer Handschriften hat, die nur noch in arabischen kanonistischen Handschriften melkitischer Provenienz vorliegt. Und es wird erklärbar, warum die Apologia Honorii dort ergänzend dem VI. Ökumenischen Konzil zugeordnet worden ist.

In diesem überlieferungsgeschichtlichen Prozess ist deren Text nach 641 offensichtlich mehrfach aus einer späteren Interessenlage heraus fortgeschrieben worden. Die Unterschiede im Textbestand zwischen dem lateinischen Text des Anastasius Bibliothecarius und der arabischen Tradition des Cod. Vat. syr. 130 lassen sich noch als Abblendung später unerwünschter Textstellen oder Verschärfung von Forderungen aus späterer Perspektive erklären. Im Kern der theologischen Argumentation des Briefes sind dem ursprünglichen Text aber bereits im 7. Jh. - wohl nach 681 - je eine Textpassage vor- und nachgeordnet worden. Ursprünglich bot der Text einen in sich kohärenten theologischen Gedankengang, in dem der Versuch unternommen wurde, die Aussage des Honorius von dem einen Willen Christi allein auf dessen menschliche Natur zu beziehen. Dabei lässt dieser Text noch die aktuelle Problemlage des Jahres 641 durchscheinen. Er signalisiert noch Bereitschaft, auf potentielle Einwände einzugehen und enthält Ansätze zu einer Verständigung. In den beiden Ergänzungen dagegen wird nun in einer typisch maximianischen Argumentationsweise aus einem ontologischen Naturbegriff ein zweifaches „naturhaftes“ Willens- und Handlungsvermögen Christi abgeleitet. Damit aber sind dem Text Aussagen zugewachsen, die im Widerspruch zu Formulierungen desselben Briefes stehen, die historisch anachronistisch und falsch sind und die die innere theologische Argumentation des Briefes als Ganzes ad absurdum führen. Im selben Sinn hat auch die römische Synode unter Iohannes IV. eine Fortschreibung ihrer Beschlüsse erfahren.

Für das Jahr 641 ergibt sich damit, dass die von der römischen Kirche nach der Intervention des Maximos Homologetes durch die Entsendung des Anastasios Monachos nach Rom eingeleitete religionspolitische Wende unter Iohannes IV. noch nicht von jenem zelotischen Geist totaler Konfrontation ergriffen war, der Maximos und seinen Anhängern eigen war. ${ }^{283}$ Trotz des deutlichen Protests gegen

283 Dazu vgl. oben Fußnote 272. 
die Maßnahmen des Pyrrhos und der Forderung nach Außerkraftsetzung der Ekthesis war die theologische Gesprächsbereitschaft noch nicht der ultimativen Erwartung gewichen, ein bestimmtes, angeblich in der kirchlichen Überlieferung verankertes Theologumenon als Dogma zu übernehmen. Dies sollte erst unter dem griechischen Papst Theodorus I. der Fall sein. Insofern ist die Apologia Honorii Papst Iohannes IV. nicht der erste römische Text mit einer eindeutigen dyotheletischen Aussage im Sinne der maximianischen Argumentation. Ein solcher Text liegt erstmals ${ }^{284}$ in der Rede Papst Martins I. zur Eröffnung der Lateransynode am 5.10.649 vor. ${ }^{285}$ Diese Rede aber ist wie alle Reden der Synode vorher von Maximos und seinen Schülern verfasst worden. ${ }^{286}$ Es ist allein Maximos, der erstmals in den Jahren 640/41 in seinen Opuscula 6, 7 und 20287 das Theologumenon des doppelten Willens Jesu Christi in konstistenter Argumentation entwickelt hat.

284 Papst Theodorus I. wird diese Argumentation wahrscheinlich bereits 646/47 in seinem allerdings nicht erhaltenen Brief an Patriarch Paulos II. verwendet haben. Dies lässt sich angesichts der Antwort des Patriarchen (Winkelmann, Streit, wie oben Fußnote 1, Nr. 104) aber nur vermuten.

285 Concilium Lateranense a. 649, ACO ser. II 2,1 p. 12, 21-14, 15 (RIEDINGER).

286 Vgl. dazu die Studien von R. RIEDINGER, in ders., Kleine Schriften (wie oben Fußnote 260). $287 \mathrm{Zu}$ diesen Opuscula s. oben Fußnote 15-18. Zur dortigen Entwicklung des Dyotheletismus vgl. J.-C. LARChET, Saint Maxime le Confesseur, Opuscules théologiques et polémiques. Paris 1998, 27-33, 43-49, 50-58. 
